\title{
The influence of nursing curriculum in associate degree nursing programs on the development of nursing professionalism in graduating nursing students
}

\author{
Cristina M. Riter \\ West Virginia University
}

Follow this and additional works at: https://researchrepository.wvu.edu/etd

\footnotetext{
Recommended Citation

Riter, Cristina M., "The influence of nursing curriculum in associate degree nursing programs on the development of nursing professionalism in graduating nursing students" (2010). Graduate Theses, Dissertations, and Problem Reports. 2973.

https://researchrepository.wvu.edu/etd/2973

This Dissertation is protected by copyright and/or related rights. It has been brought to you by the The Research Repository @ WVU with permission from the rights-holder(s). You are free to use this Dissertation in any way that is permitted by the copyright and related rights legislation that applies to your use. For other uses you must obtain permission from the rights-holder(s) directly, unless additional rights are indicated by a Creative Commons license in the record and/ or on the work itself. This Dissertation has been accepted for inclusion in WVU Graduate Theses, Dissertations, and Problem Reports collection by an authorized administrator of The Research Repository @ WVU. For more information, please contact researchrepository@mail.wvu.edu.
} 
The influence of nursing curriculum in associate degree nursing programs on the development of nursing professionalism in graduating nursing students

Cristina M. Riter, RN, MSN

Dissertation submitted to the College of Human Resources and Education

at West Virginia University in partial fulfillment of the requirements

for the degree of

Doctor of Education

In

Curriculum and Instruction

Approved by

Dr. David Callejo, Ed.D. Chair

Dr. Patricia Obenauf, Ed.D.

Dr. Donna Lukich, Ed.D., MSN, RN

Dr. Ernest Goeres, Ph.D.

Dr. Samuel Stack, Ph.D.

Department of Education

Curriculum and Instruction

Morgantown, West Virginia

2010

Keywords: curriculum; nursing; professionalism; associate degree; nursing shortage; education

Copyright 2010 Cristina M. Riter 


\begin{abstract}
The influence of nursing curriculum in associate degree nursing programs on the development of nursing professionalism in graduating nursing students

\section{Cristina M. Riter}

Nursing professionalism is assumed to develop during the educational process, with the model of the baccalaureate degree program. There have been few studies on the development of professionalism in beginning nursing students, especially those in a two-year associate degree nursing program. This research study explored the concept of professional development in reaction to the increased number of associate degree registered nurses in this country since the inception of the associate degree nursing programs in the 1950s. The impact of the registered nursing shortage on the nursing profession and the educational preparedness of future registered nurses was also explored. The research question, "How does nursing curriculum impact the development of professionalism in associate degree nursing programs?" was explored. This qualitative study is a descriptive cross sectional study with a linear frame model examining the relationship between educational content captured and the development of nursing professionalism.
\end{abstract}


Table of Contents

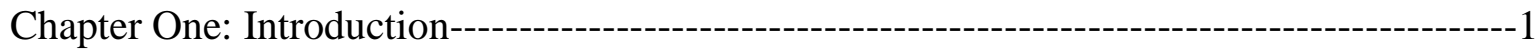

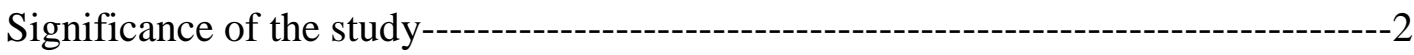

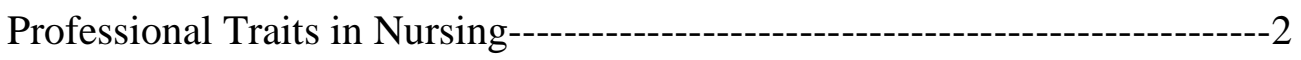

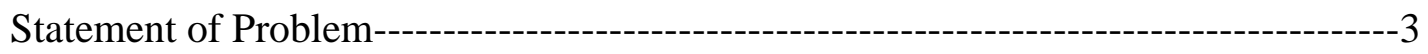

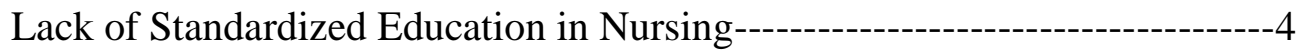

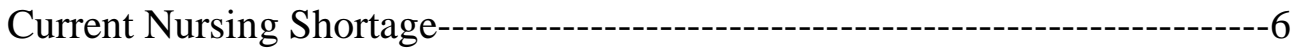

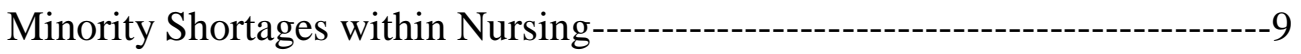

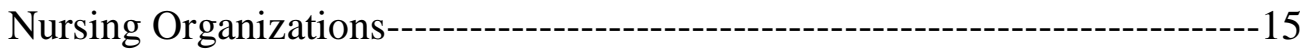

Research question-------------------------------------------------------------------------------17

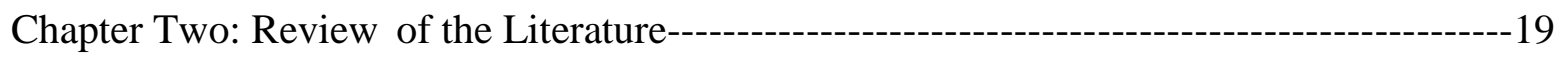

Conceptual Framework------------------------------------------------------------------------19

Theoretical Underpinnings---------------------------------------------------------------------23

Historical Development------------------------------------------------------------------------25

Development of Nursing Curriculum-------------------------------------------------------31

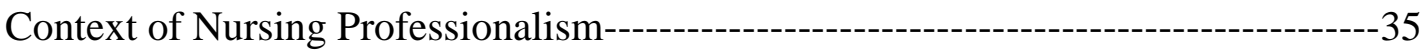

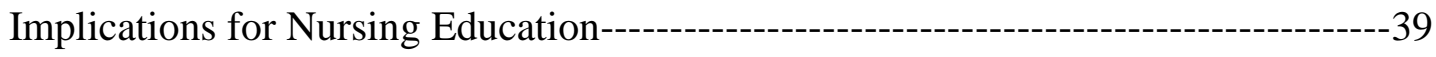

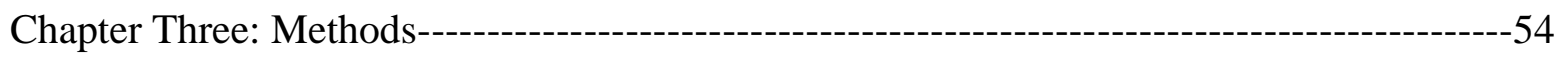

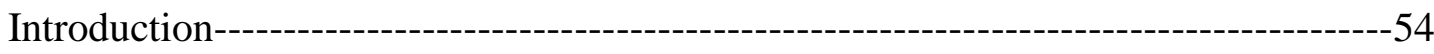

Research Methodology -------------------------------------------------------------------------55

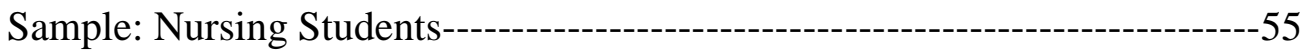

Sample: Registered Nurses------------------------------------------------------56

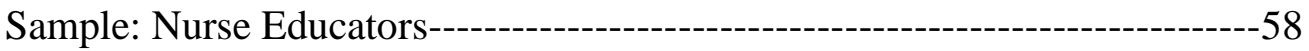

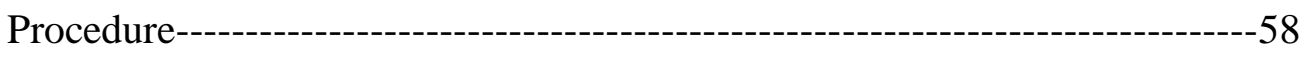




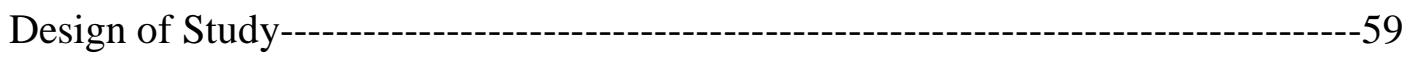

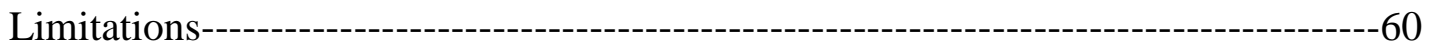

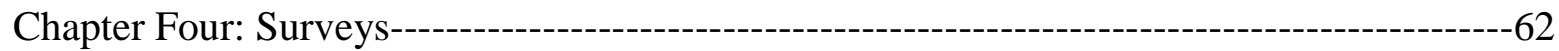

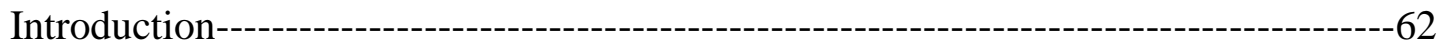

Results-------------------------------------------------------------------------------------------63

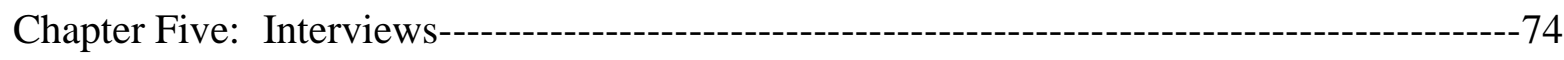

Introduction----------------------------------------------------------------------------------------74

Results-------------------------------------------------------------------------------------------74

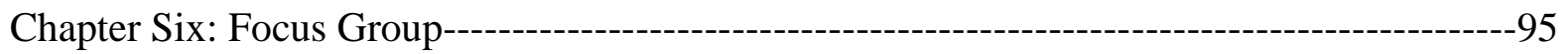

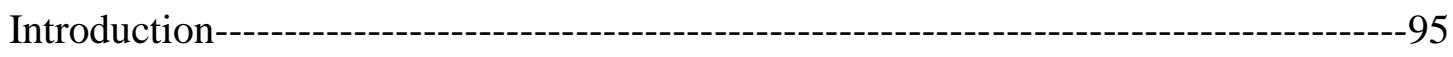

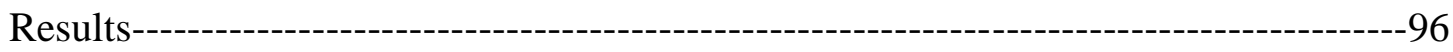

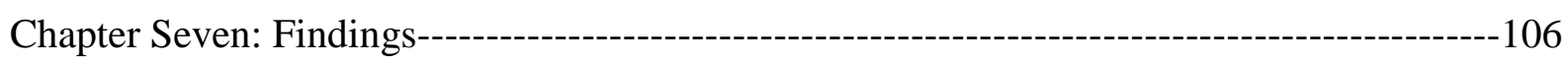

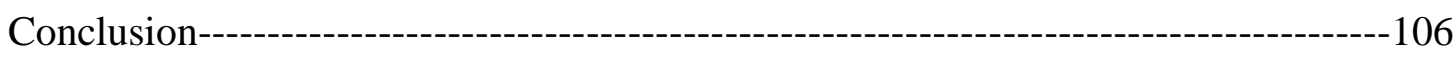

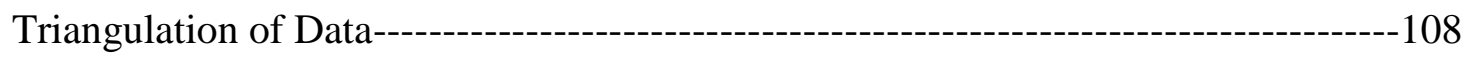

Recommendations within Current Reality-------------------------------------------------110

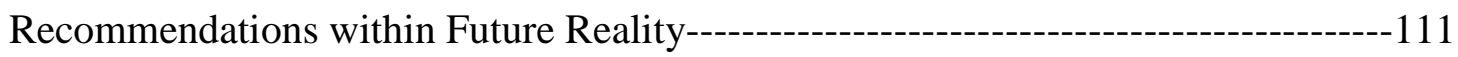

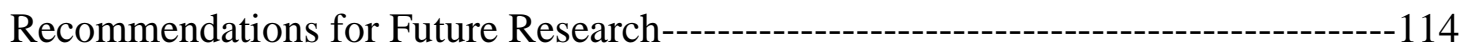

References----------------------------------------------------------------------------------------------------115

Appendix----------------------------------------------------------------------------------------------------122 


\section{Chapter I}

Introduction

The development of nursing professionalism will be explored throughout this dissertation. The historical establishment of nursing, nursing research, and nursing professionalism will be discussed in this chapter. The impact of nursing shortages on nursing education will be explored for the effect on the body of nursing as it is today. The impact on the non-white registered nurses and male registered nurses by nursing organizations and nursing education will be discussed. The creation of the two-year associate degree registered nurses will be researched and the evidence of the changes for the body of nursing, including both positive and negative views, will be presented. This chapter will discuss nursing professionalism in relation to nursing curriculum and establish the importance of nursing curriculum on the development of nursing professionalism in graduating nursing students. The current three different entry level educational programs for registered nurses will be explored and strengths and weaknesses of each program will be presented. The history of nursing practice as it is intertwined with the history of nursing shortages will be discussed.

What is nursing? The answer has been in contention since the $19^{\text {th }}$ century and the fact that it is still a question in the current $21^{\text {st }}$ century gives an indication of the scope of the problem. History supports that it is difficult for nursing to define itself; the outside forces that have shaped the definition of nursing and the role of the nurse and the internal struggles within the nursing body itself have strongly influenced the identity of nursing. Florence Nightingale, the historically credited first nursing theorist, probably did not realize that she was foreshadowing the problem of nursing identity when she stated in Notes on Nursing in 1860, "I use the word nursing for want of a better" (p. 8). What educational requirements are necessary to become a 
registered nurse? There are major inconsistencies between the educational levels of a three-year diploma nursing graduate who has no college credit, a two-year associate degree nursing graduate, a four-year baccalaureate degree nursing graduate, a six-year master degree nursing graduate and a doctorate-level nursing degree graduate; all are essentially the same as registered nurses, as long as they pass the national registered nurse licensure examination. As nursing continues to define itself as a profession, it is in question at what entry level educational preparation nursing professionalism is developed. The purpose of this study is to investigate the influence of nursing curriculum in associate degree nursing programs on the development of nursing professionalism in the graduating nursing students. The determination of that factor can have implications within nursing as nursing continues to develop into a profession with a self directed identity.

Significance of the study

The value of nursing research is conceived to generate new knowledge to contribute to the practice of nursing, specifically what the profession of nursing has defined as professionalism. The creation of a specific body of knowledge and the application of those findings into practice is a determining characteristic that guides the profession of nursing (Catalano, 2006). Catalano (2006) lists the professional traits associated with nursing are accepted in the field as:

High intellectual level; High level of individual responsibility and accountability; Specialized body of knowledge; Knowledge that can be learned in institutions of higher education; Public service and altruistic activities; Public service valued over financial gain; Relatively high degree of autonomy and independence of practice; Need for a well 
organized and strong organization representing the members of the profession and controlling quality of practice; A code of ethics that guides the members of the profession in their practice; Strong professional identity and commitment to the development of the profession; and Demonstration of professional competency and possession of a legally recognized license (p. 5).

Nursing studies are guided by strict guidelines in an effort to generate unbiased and trustworthy responses to nursing practice questions. Research is established to contribute to the professional status of nursing (Houser, 2008). There remains a serious schism between the generation of health promotion and prevention knowledge in nursing and application into practice. Researchers perceive this as a failing of nursing education in promoting research in this area, signifying the importance and power of nursing research (Pender, Murdaugh \& Parsons, 2002) to nursing. Nursing practice is based upon nursing knowledge which is generated and disseminated through literature, application into practice and further research. Nursing is considered a younger profession with disciplined investigative practitioners who contribute to the body of knowledge. Research is not problem solving but applicable to the profession as a whole. The National Institute for Nursing Research promotes this scholarly activity with financial support and establishment of research priorities (Houser, 2008). It is essential to bring nursing research into nursing education so the students learn to read, understand and apply research. More importantly is the development of the concept of understanding that nursing research is an activity that graduates will be able to do as registered nurses. Evidence-based practice establishes interventions guided by the knowledge gained through nursing research; the research has a direct impact on the quality of patient care (Catalano, 2006). This research study is 
a scholarly activity investigating the influence of nursing curriculum on the development of nursing professionalism in graduating nursing students. I hope to impact nursing education to positively affect the professional concept of registered nurses, translating into a higher level of nursing care provided.

Nursing professionalism was designed in the 1950s using sociological theories and the accepted ideals of society, such as the American Nurses Association's focus on professionalism with a code of ethics, which reflected the social manners and morals of the times. Three of the seventeen tenets are that the Golden Rule should guide the nurse in professional relationships; the nurses in personal life should adhere to the standard of ethics determined by the professional role of the nurse; and the personal actions of the nurse should be congruent with the community norms and expected behaviors in the society in which they live and work (Hein, 2001). It is the professional traits of a body that differentiate the role as professional worker from that of a technical laborer. Registered Nursing is a profession based upon having the following characteristics: authoritative control of its own work and an exclusive body of knowledge, extended period of education and self regulation, specialized competence and control over work performance, credentialing method to determine competence and legal enforcement of the professional standards defined by the body, ethical practice and intrinsic rewards, existence of collegial subcultures such as professional organizations, and public acceptance. A major problem with professionalism in nursing is the lack of a standardized education for entry level into the role of the registered nurse. The nursing body and allied health professionals voice the question of why the entry level into nursing is so much lower than the admission requirements into other health care professions. The controversy surrounds the skill level of a nurse versus the knowledge base. Should nursing be a vocational trade instead of a profession? Will nursing fail 
to maintain the strides that they have gained in establishing nursing as a profession? Nursing has the designation of being the least educated for entry level requirements than any of the other health care professions (Huston, 2010). This problem is compounded because it is then transferred into all aspects of registered nursing education (Hood, 2010) with diploma nursing program graduates, associate degree nursing program graduates, and baccalaureate nursing program graduates all prepared and eligible to take the national licensure examination for licensure as a registered nurse. Nursing professionalism is assumed to develop during the educational process, yet where in the educational process that nursing professionalism actually develops. This is further complicated by the variation in entry education levels within nursing. A study examining the socialization of diploma school nursing students, associate degree nursing students, and baccalaureate degree nursing students (Alutto, Hrebiniak \& Alonso, 1972) found that the ideology of nursing professionalism is expected to transfer across the diverse groups of education, gender and ethnicity; yet it does not. The study discovered that graduates had different role expectations dependent upon their educational degree and this affected the concept of nursing professionalism. Haase (1990) states that the declaration of the American Nurses Association that the baccalaureate degree become the minimal educational foundation for professional registered nurses resulted in disharmony among nursing educators of different nursing program types, such as diploma and associate degree. All nursing education programs have the responsibility to assist students in developing professional identity, which is essential for professional nursing practice. The nursing programs should include a variety of experiences, including didactic and clinical. It is important to assess beginning student nurses' definitions of nursing and develop curriculum to enhance professional identity for the student. Curriculum should be developed to introduce information related to professional identity development, such 
as ethics, communication, and cultural competence (Cook, Gilmer, \& Bess, 2003). The

established professional traits for nursing can then be translated into curriculum which promotes professional behaviors. With over forty percent of the current registered nurse population from associate degree program educational levels (Joel, 2003), the increasing popularity of the associate degree nursing programs is evidence of the importance of establishing professional behavior among the graduates. The essential professional knowledge and behaviors, including skills, values, and attitudes, are the responsibility of the nursing faculty and should be formally taught to the nursing students (Fetzer, 2003). The multidimensional problem to the educational process for registered nurses involves nursing shortages and it is further complicated by these shortages.

\section{Current Nursing Shortage}

The current shortage of registered nurses has forced nursing education to examine how nursing curriculum addresses the development of nursing professionalism in the graduates. For most of us, we see changes in health care, such as the nursing shortage, as a personal experience in an individualized way before realizing that the problem is more widespread. This experience can be personal when a health care crisis is realized by a family member or a friend; it does not have to be self realized for it to be traumatic. Many patients in medical settings have experienced the shortage of registered nurses. The predictions for the intensity of registered nursing shortages estimate 200,000-500,000 in this country with serious concerns of catastrophic nursing shortages realized in 2010-2030. The shortage of registered nurses is higher in areas of nursing that involve direct patient care, such as hospitals, rehabilitation centers, nursing homes, and hospices.

Shortages of registered nurses are also noted in home care and schools, and there is great concern in the shortage of nursing faculty within this country (Gordon, 2005). Although the recruitment 
and incentives promoted for registered nurses by healthcare facilities, particularly hospitals, give the impression that nursing care is highly valued and the registered nurse providers of that valued care are respected professionals. It would appear to be beneficial to a nurse as an individual and to nursing as a body, but nursing shortages have been detrimental to nursing overall.

The shortage cycle increases the overall salary, benefits and recognition for nurses which in turn results with an increased enrollment in nursing programs across the country. When there is no longer a nursing shortage, the overall salary and benefits become more fixed. Although these shortages occur over many years, the overall effect on nursing salary and benefits is that nursing salaries will level off and stay the same for a decade, resulting in below average compensation for nurses (Pinkerton, 2001). Nursing shortages are largely regional phenomena and are closely attached to economic conditions, as the economic status decreases, enrollment in higher education increases. There is an increased demand for nurses that does not fluctuate with the financial rating of the nation and that is the increasingly older population and the healthcare needs that accompany age. This is added to the aging population of registered nurses taking retirements at a time in history when there are increasing numbers of adults needing nursing care. Healthcare facilities experiencing budget cuts have often reduced the number of nurses and have discovered that it has a long term result disastrous to the quality of healthcare (Catalano, 2006).

Hospitals, rehabilitation centers, nursing homes, and hospices that involve more direct patient care result in a visible change to the patient and patient family in the patient to nurse ratio. Home care and schools are also areas in which a decrease in the time the nurse spends with patient and students make the shortage more visible. Nursing faculty shortages are visible in the college classrooms. The continued predictions for a registered nursing shortage in this country 
within the next 20 years raise serious concerns of just how far reaching the effects will be (Gordon, 2005).

Impact of Past Nursing Shortages on Nursing Education

The educational preparation for registered nurses can be accomplished through a variety of programs such as diploma programs, associate degree (AD) programs, and baccalaureate degree in nursing (BSN) programs. The historical diploma nursing programs were established in the hospitals during the early nineteenth century and provided no formal, higher education preparation for nursing but trained young, unmarried women in the apprenticeship type of schooling (Joel, 2003). The diploma programs were encouraged to educate and provide registered nurses in response to the growth of hospitals in the early $20^{\text {th }}$ century. The medical advances during this time in history, such as new drug therapies, longer life expectancies and the establishment of health insurance all resulted into more patients needing nursing care. Criticism of the diploma schools included that the nursing students were being used as an inexpensive source of labor (Malka, 2007). The associate degree programs were developed in response to the severe nursing shortages after World War II and were valued because the registered nurse could gain the education they needed in a two year period, as opposed to the three years necessary for the diploma nurse (Malka, 2007). Mildred Montag created the newest form of registered nurse education, the associate degree nursing program, in 1951 as a result of planned research and controlled experimentation for her doctorate dissertation. The education preparation in the associate programs is usually done at a community college level, but is not restricted to that format. The student must complete general educational and science course requirements. The associate degree attracts a diverse student population of older students, married students, and minorities (Zerwekh \& Claborn, 2006). The educational process of the baccalaureate degree 
programs in the historical scope of nursing education was started with the first autonomous college of nursing at Yale School of Nursing in 1923. The nursing student who meets the general education, science and major subject requirements of a four year program attains a full academic degree of baccalaureate in science nursing degree (Catalano, 2006). The focus in the 1970s was to move the learning experience of the baccalaureate prepared nursing students from the hospital focus to the community because nursing leaders believed that nurses would never gain autonomy and independence unless they removed the nursing students from the domain of the physicians, which was the hospital itself (Malka, 2007). Regardless of the educational path, each nursing school graduate of a recognized nursing program is eligible to take the National Council Licensing Examination for Registered Nurses (NCLEX-RN) for licensure as a registered nurse (Zerwekh \& Claborn, 2006).

Minority Shortages within Nursing

\section{Male Minority.}

The presence of men as nurses, although few in number, are recorded before World War II; it may be society's view of the powerlessness of females and roles associated with females that prevented many males from desiring to join the nursing ranks. The male nurses graduated from all male colleges and were not accepted into the American Nursing Association until after World War II (Joel, 2003). The influence of feminism on the role of the nurse has strongly shaped the essence of the registered nurse. During the eighteenth century efforts to have nursing established and recognized, the medical establishment would allow nurses to function as long as the role was understood to be a role of caretaker and mother. The nurses were to be the social, educational, and economical equals of the patients and not the higher level physicians (Gardner, 2005). The perception that nursing remains a female profession may be forced to change, if the 
continued rate of increased numbers of male nursing students continues. The surprising problem with the male registered nurses is that they are leaving the profession faster than their female counterpart, yet another factor in the development of an increasing shortage of registered nurses. The role of a male as inappropriate to provide care is an underlying perception in society.

Bell-Scriber (2008) explored the experience of the male nursing student and discussed factors outside the college experience included lack of support for the male student in nursing, being questioned and teased about why a man would want to become a nurse and the unfamiliarity of being with women as classmates and coworkers. The nurse educators in this study were female as were all references to nurses within the textbook causing the male nursing student to see the closely tied association of female and nursing. Bell-Scriber (2008) found that female nursing educators communicated messages that were negative such as looks, gestures, tone of voice and inference which resulted in the male nursing student questioning their worth and their dedication to nursing. The McMillan, Morgan and Ament (2006) study exploring if female registered nurses accept male registered nurses was conducted in a large Midwestern state in America, including rural and urban areas. The study found that the rural group of registered nurses most often had associate degrees and the urban group of registered nurses predominately has baccalaureate degrees. Regardless of the educational preparation or age of the female registered nurse, the strongest determinant of acceptance by a female nurse of a male in the role of registered nurse was the amount of time the female nurse worked with the male nurse. The longer the female registered nurse worked with the male registered nurse, the more likely the female nurses were to accept the male nurses in the role of registered nurse (McMillan, Morgan \& Ament, 2006). 
The following quote is the perception of a male registered nurse working in a rural health model on the impact of his gender in nursing school and now in nursing practice. He is a 2007 diploma level nursing school graduate from a nursing school in the same geographical area as the hospital in which he works. He came into nursing after working in an industrial setting for five years. When he lost his job due to downsizing, he decided to follow his dream of working in healthcare.

I have noticed a lot of difference, male to female, especially in nursing school. I am not outgoing or the life of the party and I did feel treated differently in nursing school. The other students included me in things but I felt more of a loner. Now in nursing as a whole, things are a 100\% turnaround. I get along with everyone. I do, though, see how men are used more for lifting and things, but patient assignment equality is given. I don't get bad or good patients over others. Some female nurses are more willing to help and lend a hand now as opposed to nursing school. I don't feel that I am treated any differently from the higher up personnel than women are. Now days I feel we are more accepted into the field than before and I have even heard the ladies say, what did we do before men came around? Ironic, isn't it, in the age of liberation, we are needed and wanted more than before.

The perceptions of 489 male registered nurses were investigated to determine why so few men join the ranks of registered nurse (Hart, 2005). Men revealed that they choose nursing because of a desire to help others, the multiple career paths of nursing, and the availability of steady job opportunities. The self concept of being a male nurse was identified as awkward in almost half of the respondents. Barriers to men becoming nurses were listed as the traditional female role of nursing, public perception that male nurses are gay and lack of role models. 
Nursing school difficulties were feelings of being in the minority, being used for physical strength in the clinical setting, and being thought of as uncaring. The investigators state that the male nurses expressed passion and caring in talking about nursing and communicated the positive feeling of making a difference in the life of another as rewarding in nursing (Hart, 2005).

\section{African American Minority}

African American females were able to break the prejudice barriers against their race to become registered nurses, but it was very difficult for black women to become nurses. The National Association of Colored Graduate Nurses (NACGN) was formed in 1908 and focused to combat discriminatory practices. The American Nurses Association had a nondiscrimination policy but required that nurses must graduate from a state supported school to become a member and many states were discriminatory, so there was round-about discrimination policy preventing black nurses from becoming American Nurses Association members (Joel, 2003). Nursing continues to lack in racial and ethnical diversity. Minority populations are underrepresented with only $12 \%$ of registered nurses nationally identifying themselves as being a racial or ethnic minority in the year 2000 in which $31 \%$ of the general population described themselves as being a racial or ethnic minority (Gardner, 2005). The American Association of Colleges of Nursing (AACN) has encouraged all nursing programs to actively recruit and retain more minority students with the stressed importance of minority role modeling. The failure of minority students in nursing programs has been attributed to feelings of isolation, distancing, discrimination and cultural ignorance on the part of faculty and students. Each nursing program should institute strategies for minority retention in their schools (Gardner, 2005). 
In Colman's study (2008), the perceptions of African American nursing students enrolled in a predominately white two-year institution were explored in a qualitative pilot study in a community college in a suburb of Chicago, Illinois. The themes of difference, coping and survival, support systems, and institutional context were used to reveal the existence and influence of the saliency of race. The study found that minority students perceived that nonminority students and faculty responded to them differently based upon their physical appearance and behaviors. The African American students felt that the reality of a lack of support and failure of acceptance pushed the African American student to develop and use coping strategies, using overt and covert behavior strategies. This situation resulted in another impediment to the development of relationships with nonminority students and educators. The lack of support felt by the minority students was attributed to nonminority classmates, nursing faculty, and college environment. The African American nursing students also expressed the feeling that colleges are unwelcoming and lacking in cultural and racial sensitivity (Coleman, 2008).

The power of nursing faculty in providing support is demonstrated in a formation of a minority nursing support group; at an area community college, there is a support group for African American nursing students which meets about three times each semester with an African American registered nurse graduate of an associate degree nursing program who serves as the facilitator for the meetings. Recently, when asked if any of the students would like to record their perceptions of what the group means to them, a second-year female African American nursing student expressed this view. She writes:

For me having the opportunity to have a chance to meet with others from my same race and share our experiences in this program really helped with my success 
thus far. When I began, I walked into a class of 40 plus persons and I stood as the one and only Black American and to which in some degree made me feel uncomfortable and out of place and to be able to speak with someone who stood where I stood and may have experienced the same feeling that I felt; really it was supportive and gave me to some degree more confidence to keep up with the program. It really helps me to also feel as if someone is looking deeper into what makes another person succeed beyond just curriculum and grades but to also try and see what further influences does a person have on the success not only in school but life as well. And it really appealed to me that when people care and dig deeper beyond surface measures it can have a profound effect on a person's outcome.

Literature clearly documents a failure on the part of nursing education to meet the needs of the minority population. In a current nursing education study in California, community college statistics reveal a higher first time pass rate on National Council Licensure Examination for Registered Nurses (NCLEX-RN) for colleges with lowest numbers of minority students, child care programs, tutoring or remediation studies and an absence of any learning resource center (Seago \& Spetz, 2005). This study suggests that the curriculum and teaching strategies available fail to meet the educational needs of minority students. Minority students have diverse learning needs which differ from the dominate Eurocentric perspective in such areas as multiple choice testing formats, the structure test question on the National Council Licensure Examination for Registered Nurses (Giddens, 2009).

A research study looking at barriers and facilitators which affect further education by African American registered nurses that are baccalaureate degree nursing program graduates or current baccalaureate degree nursing students was recently completed in a Midwestern region of 
the country. The 75 question survey was mailed to 33 eligible nurses and 19 questionnaires were returned to the researcher. Barriers and facilitators of academia, finance, aspiration, and institution were explored. Results of the study determined that many inner city schools did not adequately prepare the African American students for success in college; African American students were not guided into college preparation classes and were not well informed about nursing programs and degrees. The surveys of a majority of subjects said that they did not receive encouragement from high school counselors and administrators. Respondents in an overwhelming majority stated that parents expected them to attend college and a large majority reported family members who attended college. Institutional barriers were a lack of faculty support, yet the majority felt that there was some support and nurturing within the nursing program by both faculty and students (Mingo, 2008). The failure of providing information to college-bound high school students about nursing programs has decreased the number of potential registered nurses and is yet another example of factors contributing to a registered nursing shortage in this country. Within the national nursing shortage subcategory of African American registered nurses, this failure of providing information to college-bound high school students that are African American likely has done immeasurable damage to decrease the numbers of potential registered nurses within the African American population.

\section{Nursing Organizations}

\section{With a Focus on Quality of Nursing Practice}

Nursing organizations function to empower nurses in the profession of nursing and some represent all nurses while other organizations focus on specialty nursing interests. The American Nurses Association (ANA) is represented as a nursing organization for all registered nurses and has been in existence since 1908. The American Nurses Association is concerned with legislative 
issues and policy matters, supports the American Nurses Credentialing Center (ANCC) for certification of nurse specialists, and accreditation of nursing programs (Zerwekh \& Claborn, 2006). The American Nurses Association, in 1965, published a paper defining the scope of nursing practice and defining the baccalaureate education as the entry level preparation for registered nurses (Catalano, 2006). Nursing has demonstrated the increasing political involvement with the organization of the American Nurses Association Political Action Committee (ANA-PAC) which has been active in promoting the legal, economical and social concerns of nurses since the early 1970s (Hein, 2001).

The National Council of State Board of Nursing (NCSBN) is the organization that prepares and regulates the national licensure test for the registered nurse, called the National Council Licensure Examination for Registered Nurses (NCLEX-RN). The candidates taking the National Council Licensure Examination for Registered Nurses in 2009 included baccalaureate degree program graduates 52,241 with $89.49 \%$ pass rate and associate degree program graduates 78,655 with $87.61 \%$ pass rate. This reflects a similar pattern when compared with 2008; baccalaureate degree program graduates 49,739 with $87.5 \%$ pass rate and associate degree program graduates 75,545 with $86.2 \%$ pass rate and 2007 ; baccalaureate degree program graduates 45,781 with $86.4 \%$ pass rate and associate degree program graduates 69,890 with 84.4\% pass rate (https://www.ncsbn.org). The numbers demonstrate the ability of the two-year programs to prepare nursing students with the knowledge and skills they need to compete successfully with nursing students prepared over four-years of college to begin employment as registered nurses in entry level nursing positions. In comparing the number of nursing graduates taking the national licensure test for registered nurses between baccalaureate degree program 
graduates and associate degree program graduates, $60 \%$ of the graduates taking the test are graduates from an associate degree program.

\section{With a Focus of Quality of Nursing Education}

The National League for Nursing (NLN), a nursing organization which acts on behalf of both individual nurses and nursing agencies, began as an entity in 1952 but originally was formed after mergers of other educational and nursing organizations dating from the late 1800s. The National League for Nursing promotes improvements in nursing education and nursing services and created an organization, the National League for Nursing Accrediting Commission (NLNAC), which accredits nursing programs. The National Student Nurse Association (NSNA) was organized in 1952 for nursing students and provides the opportunity for nursing students to begin a professional socialization. The National Organization for Associate Degree Nursing (NOADN) was created with a combination of state organizations in 1984 to advocate for the associate degree nursing programs in community, state and national forums. The American Association of Colleges of Nursing (AACN) focuses on improving nursing research, education and practice. The American Red Cross is an international organization with the role of meeting the needs of those persons affected by disaster with nurses providing care (Zerwekh \& Claborn, 2006).

\section{Research Question}

The standards for the dimensions of both professional and practical nursing are reviewed and updated by the American Nursing Association (ANA). There are almost three million registered nurses in this country, making them the largest group of health care providers. The eight dimensions of nursing as a profession are defined as:

A profession has relevance to social value; 
A profession has a training or educational period;

Elements of self motivation address the way in which the profession serves;

A profession has a code of ethics; A profession has a commitment to a lifelong work;

A profession is controlled by the members of that profession; and

A profession has a theoretical framework on which professional practice is based

(Zerwekh \& Claborn, 2006, p. 183).

Given the standards and dimensions of nursing professionalism, this study attempts to discuss the research question, "How does nursing curriculum impact the development of professionalism in associate degree nursing programs?" Second, other subsidiary questions that emerge from the primary question will be analyzed also, including, "How can nursing associate degree programs address the nursing shortage within their context of ethics and practice?" and "How can nursing maintain its professional identity within the curriculum changes that will be necessary to meet the nursing shortage?" 


\section{Chapter II}

\section{Literature Review}

\section{Conceptual Framework for Nursing Curriculum}

This chapter will lead the reader through the nursing theory and curriculum theory that provides the framework for nursing curriculum. The associate degree nursing program is delivered at the community college level and this chapter will discuss how the life experiences and life responsibilities of students impact the teaching and learning. The history of nursing practice and nursing education will be investigated so we can understand how the influence of those historical actions is evident in nursing practice today. The changes in nursing in response to historical events are discussed. The beginning of the establishment of nursing professionalism will be explored and the quest for the continued development of nursing professionalism will be investigated. The public perception of registered nursing will be discussed to seek how this affects the self concept of nurses. The advent of technology will be discussed in relation to what nursing must do to adapt to the challenges that technology presents in teaching and learning. Curriculum theorists and nursing theorists will be explored to discover the power of curriculum on education in general, and nursing education specifically.

Nursing knowledge is information captured from many different sources and experiences and essentially reflects reality. This knowledge is gained from classroom and clinical experiences in nursing education. The educational opportunities enable the nursing student to learn the content, then process and apply the nursing knowledge into care for the patient (Burns \& Grove, 2003). Nursing knowledge recognizes fundamental patterns of knowing in nursing education. The goal of nursing education is for the student to develop into a thoughtful, knowledgeable, caring nurse who is competent in providing nursing care. It must not be 
overlooked that each patient and each patient's health status and each patient experience is different each and every time. Therein lies the issue, how can a person be prepared to meet the needs of the patient on the multiple levels of need: mind, body and spirit? Research has validated the connection between thoughts, emotions, and physiology (Hein, 2001) with an easy example of the mind, body, spirit reaction to stress. The mind races with thoughts and apprehensions, the blood pressure, heart rate and respirations increase, and the spirit reacts with a depressed, hopeless outlook. The patterns of knowing, first developed by Florence Nightingale, guide the nursing education today and demonstrate the complexity of nursing education. The concept of knowing within nursing is difficult to study because of the multidimensional environment which encompasses nursing practice. Nurses intertwine realms of knowing with personal experiences and it is demonstrated with the nurse understanding the difference between the scientific knowledge about the disease process and the patient experience of living the disease (Bonis, 2009). Nightingale's theory placed the patient in the center of the model and then integrates psychological, intellectual, and spiritual components, which exemplifies the Nightingale concept of holistic care, promoting health as well as treating illness. Each of these Nightingale components are termed domains of knowing and each addresses a different piece of the overall dimensions of the role of the nurse. Each pattern is necessary to meet the needs of the patient and requires the nurse to enter into a relationship with patient that is unique to that patient, at the time and in that circumstance.

Empiric knowing, or science of nursing, is what is learned through the senses and is based on reality that can be observed and experienced. There is a cognitive component with problem solving and logical reasoning, but this knowing is in the unconscious realm of learning (Chinn \& Kramer, 1999). Understanding how the heart pumps blood through the body allows the 
nurse to understand the physical manifestations when there is an alteration in the pumping action. By understanding that blood not pumped through the lungs will cause congestion in the lung fields provides an example of empiric knowing. The nurse knows to listen to the lung sounds and assess the breathing based on the scientific knowledge of cardiac function.

Ethic knowing, or morality of nursing, is what is beyond the normal and ethical codes of nursing and society and encompasses the ongoing decisions concerning what is good and right and responsible. Ethical knowledge provides insight into what choices are possible and why they are viable solutions. This is expressed in the ethical component of nursing practice. This knowing is the guiding principle in decisions such as how to conduct nursing care, how to prioritize nursing care, and in what situations and experiences require advocacy. These are value declarations that cannot really be confirmed scientifically (Chinn \& Kramer, 1999). This knowing guides the nurse in performing the actions that are entrusted to the nurse. For example, when a medication is ordered for a particular patient, it is the nurse who is responsible for fulfilling the care of administration. Ethic knowing causes the nurse to thoroughly check that all parameters are correct, that the correct patient receives the correct medication in the correct dose by the correct route at the correct time. If there is a mistake in any part of this process, it is ethical knowing that the nurse uses in reporting the mistake and taking whatever actions would follow.

Personal knowing, or truly understanding self, is knowing the relationship between self and others through the eyes of self. It is the combination of knowing self, knowing others, being in the environment and in the experience that combines to make a meaningful, shared human experience. This is expressed in the therapeutic use of self in healing encounters in nursing practice. Personal knowing becomes stronger with age and the wisdom developed by life 
experiences. This knowing is a part of every encounter for every human being as we only experience an event through the filter of our own senses and sensibilities (Chinn \& Kramer, 1999). Personal knowing is an aspect of nursing that is strengthened by the adult having the resources and institution available to become a nurse. The university and college nursing programs have a high number of young students, those who have recently completed high school. The community college nursing programs have an average student age of about thirty years, with admitting policies based upon ability and not age. This allows the education of nurses who have rich experiences in life and more easily expressed personal knowing which translates into higher levels of patient care.

Aesthetic knowing, or art of nursing, is what is beyond the surface of the experience to sense the meaning of the exchange and connect with the human experience such as birth, illness, suffering, recovery, death. There is no conscious consideration, the nurse gains meaning from the experience and that sense of meaning is reflected in the encounter. This is expressed through the nurse's relation to others and it allows the nurse to know what to do in the moment, gaining meaning of each encounter (Chinn \& Kramer, 1999). This importance of the art of nursing is sometimes evident in the experiences of patients with lingering psychological effects of an illness. In The Vulnerable Observer (1996), Ruth Behar recounts the physiological and psychological trauma she experienced after a tragic motor vehicle accident when she was nine years old. Her femur was broken and the physician correctly diagnosed and treated the fracture so that Behar would have no physical limitations as a result of the accident. This involved a cast covering the little girl from the midsection area and encompassing both legs and feet, with only an opening provided for elimination purposes, and a bar that ran between her feet. Behar could only be positioned on her back or flipped over on her front. At the age of 35 years, the author 
began having panic attacks and debilitating anxiety attacks that lasted until Behar processed the experience of her accident and recovery to relieve the feelings that she had suppressed.

Thankfully, she was able to recover but this terror aftermath could have been prevented if Behar would have had a registered nurse able to practice Aesthetic knowing. The nurse would have been able to connect with Behar's experience and help Behar express her feelings and guide her recovery. Behar would have been able to express her thoughts and feelings and process through them to recovery while she was physically recuperating.

Pedagogy and Identity: Theoretical Underpinnings of Nursing.

Maxine Greene discusses that the contemporary learner has a different reality than learners in the past. The abruptness of change within society has affected the learner to be less connected to his world and the perceptions of his world. This has a profound effect on both learning for the student and teaching for the teacher. Curriculum must be presented and the student must reach and make meaning of the knowledge based upon the life experiences and consciousness of the student; making each educational experience unique based upon the dynamic changing perceptions of the student and the teacher. Curriculum that is imposed or enforced will not succeed (Flinders \& Thornton, 2009). The community college serves as a place of education for adults who have matured into realizing the value of education or for those adults who need additional education to advance in their employment. The contemporary view of college and the consumerism of education are resulting in students who expect a good return for their money; this is relative to how a good return in education is defined. The student may perceive it as good grades and a degree without contributing much, if any, work but the educator should perceive it as an increase in knowledge and personal growth. Nursing educators cannot adjust to share the student philosophy as the nursing student that graduates with a degree must 
still be tested with a registered nurse national licensure. It is often amazing to learn that students want both: an easy time in college and a successful experience with licensure; ironic because that lack of knowledge is something that the registered nursing licensure examination is designed to detect, so the student has taken the path of least resistance that leads to the goal of highest resistance.

Paulo Freire (2007) addresses the importance of communication with the student; the thoughts are revealed through language which is structured by the framework of cognitive action. The language used gives voice to the reality they perceive and the perceptions of that reality. Problem posing education reaches out to the student to encourage self analysis and internalization of the concept so the student becomes an active participant in the educational process resulting in an increased understanding and in-depth knowledge of nursing. By attaching the content to the students themselves, and their experiences in the world, the student will become engaged and enter into the educational process by responding to the challenge presented to them in context of teacher, student, and student experience with the response and meaning making. As the student progresses in this way, the student gains new understandings and the development of feeling committed to becoming a nurse. The student's development is ongoing and the educator must be available for conferences and time to spend with the students. Nurse educators must also have self control, patience and the ability to change according to the situation; the community college setting has students ranging from 20 years to 60 years and the experience and world from which each student comes can be strikingly different than other students. Nurse educators must be able to teach mechanics, methods and skills in the classroom which then transfer into the clinical setting with actual patients. This must be accomplished with the educational focus of aiding the student to bring the themes and meaning that makes them 
unique and nurturing so the student can attach the new meanings and develop into a nurse who is as unique as the patient they are treating.

Nursing has been held to a dependent, subordinate profession to the medical dominance (Gordon, 2005), much like the female role in the male dominated society. Madeline Grumet (Grumet \& Stone, 2000) discusses feminism and the implications into female behavior in the years since the liberal feminism movement of the 1970s. Liberal feminism takes for granted that what women want are the lives of men. Today's female sports figures play a sport, gain attention and economic advantages, things that would not have been likely before the rise of women's consciousness. The weakness in this arrangement is, of course, that not all women want to be like a male and the pressing of liberal feminism can itself become oppressive. Role theory proposes that people model what they see, although evidence exists that not all people want to do what they see portrayed, and this includes young females. It is also important to note that middle class women are more likely the holders of power that was won by liberal feminism and the lower income women have not yet experienced it. Male and female roles are defined culturally with the male dominant and the female subordinate (Grumet \& Stone, 2000) and the female dominated profession of nursing carries the cultural female role as part of the essence of the registered nurse, whether the nurse is biologically male or female.

Contexts of the nursing profession: An exploration of historical issues

\section{Early Historical Development of Nursing}

It is difficult to trace the exact beginning of nursing as the practice as it has been in existence in some form since the beginning of man, although not necessarily in a professional. The ideas of a mother caring for her child or one family member caring for another family member are basic examples of nursing actions. The word nursing is taken from the Latin word 
nutricius, which translates as nourishing. Early mythology included and identified nursing in the Roman goddess Fortuna, responsible for fate as well as the nursing care of the god Jupiter (Zerwekh \& Clahorn, 2006). This implies that the Romans identified nursing care as something that contributes to the outcome of an illness or the promotion of good health. From these early beginnings, nursing care has had a secure place in society, although it has not always been one of professional recognition. The Egyptian physicians and nurses prescribed and applied many treatments of ancient medicine. Many of these treatments used the power of animal parts for treatments or addressed driving evil spirits from the body. Documents from 1500 B.C. reveal the role of the nurse in Egypt as midwife, injury and wound treatment, health promotion and even birth control. In the ancient world, as almost exclusively throughout history, nursing is associated with the role of the female. In Egypt, the physicians were male (Catalano, 2006). This historical close association of nursing and female must be considered when examining the establishment of nursing in a male dominated society and the consequence to nursing today.

The ancient Greek actions and writings of Hippocrates began to change medical practice. Previous to his teachings, illness was perceived to be the will of the gods and it was a standard practice to put to death humans born with any type of physical or mental deficit. Hippocrates is known as the father of medicine and his focus was a holistic view in accord with natural law, in contrast to the gods. The holistic analysis of the individual included mind, body and spirit and Hippocrates developed the idea of basing the treatment on the symptoms of the disease or illness (Catalano, 2006). The idea of treating the symptoms, or what the patient is experiencing, is a basic nursing principle in today's world of nursing. The nursing care is based upon providing care for what the patient is experiencing; the physician focuses on the disease process itself. The historical documentation of male nurses is found in the records of the Holy Wars. There were so 
many people injured during these wars that the Christian crusaders established a hospital in Jerusalem, called the Hospital of St. John, and knights served as nurses in this institution. The knights wore red crosses emblazoned on the chest of their tunics to identify them on the battle field (Zerwekh \& Clahorn, 2006).

\section{Historical Changes for the Concept of Nursing}

The Dark Ages were a time of illness and death associated with the high poverty status. Unchecked plagues and diseases such as diphtheria, small pox and the dreaded leprosy were common and experienced by many. The Christian religion was responsible for providing what health care there was. Catholic monasteries and convents took in those who were sick, and became known as centers of help. The nursing care was provided with strong religious teaching and examples of common treatments for the illnesses included bloodletting, leeching and enemas. The nurses of this time did not have any formal training in healthcare and secular orders were soon in existence to aid in the care of the many. It was during this time in history that the ideas of cleanliness and hygiene were started (Catalano, 2006). The idea of cleanliness next to Godliness may have been the motivating factor, but it was recognized that the cleanliness associated with good spiritual health was also associated with good physical health. The Protestant Reformation that began as a religious reformation caused a change in the provision of health care and nursing itself. The religious orders that provided care of the sick greatly decreased the numbers of those hospitals and the nuns who provided nursing care were greatly reduced, resulting in a nursing shortage. The Protestant world looked upon those with illnesses as burdens to society. The absence of the convent nurses was filled with women who served time in the hospital in place of prison time, former prostitutes and alcoholics (Catalano, 2006). This is 
evidence of the place of the female during that time; they were credited with being just one level above the accepted dregs of society, the sick and dying.

The historical place for nursing in the United States does not appear until about 1870, when formal training was established. The colonial period found most nursing being done in the home with the family. Nursing was either passed from mother to daughter or learned by a domestic servant as part of the duties. The caring character of women caused nursing care to be a part of the female herself and it expressed love of others. This was the society of religious beliefs being translated into the female virtues, as Catherine Beecher stated that the sick were given to the woman's compassionate care (Hein, 2001). The revolutions of intellect and industry impacted nursing care as the great masses gathered in the cities to work in factories. In addition to the scientific approach of physicians, equipment such as microscope and thermometer and the development of the printing press changed life dramatically. Further advances in healthcare was realized when Jenner developed the smallpox vaccine. The benefits to healthcare did not include birth control; only abstinence was available as a nonviolent method of population control. Infanticide was a common practice as necessary in poverty situations (Zerwekh \& Clahorn, 2006).

Nursing continued along the historical journey of development and the idea of nursing professionalism was introduced by the ideology and actions of one woman during the eighteen hundreds. Florence Nightingale envisioned nursing as an art, as opposed to a science, for which training and education was necessary. She was a woman of her times and she believed in the Victorian idea of divided spheres of activity for the male and female. The woman would develop the female virtue and this would be the basis for the care provided. The training stresses character development and taught that women had the duty to provide care, not the more modern 
ideas of the right to provide care (Hein, 2001). She was ingrained with the female hierarchy model of society and prepared women to function and thrive within it. Nightingale did this by seeking a change in class defined behavior and not a gender change of status. She rejected the accepted role of the nurse being obedient and dedicated. Nightingale believed that training for nurses should be based upon practical scientific content so the nurse would become the skilled servant of health, hygiene and medicine and not function as a servant to physician or health officials (Holiday \& Parker, 1997). Nightingale was the first nurse researcher as she recorded basic research about patient's physical and mental wellbeing, the power of the environment on patient care, and the healthiness of ventilation, cleanliness, clear water and nutrition. Her research really started during the Crimean War and she tracked the morbidity and mortality of the soldiers. Nightingale is credited with providing knowledge which contributed to public water testing, sanitation improvements, importance of nutrition, and health promotion (Burns \& Grove, 2003). Research is just one of the aspects of nursing which Nightingale would influence; her impact on nursing education continues today.

\section{Changes in Nursing in Response to World War II}

The impact of World War II on nursing is still being realized today. Nurses of different nationalities were brought together to treat the injuries that were the result of the increasing power of warfare. The Army Nurse Corps was started in 1902 and the Navy counterpart in 1908; the nursing units were to be separated from the regular forces and were all female units. The Red Cross recruited nurses in no connection with the military hierarchy (Hein, 2001). The demand for nurses of all colors created new opportunities of freedom and the Cadet Nurse Corps was established in 1943 and the Bolton Nurse Training Act is the first federal act to subsidize nursing schools with the stipulation that the nurse serve in the armed forces for the duration of the war 
(Joel, 2003). The Bolton Act also forbade discrimination on the basis of race, creed or sex. In response to the advancements in health care, nurses needed more specialized education. It is also the time that team nursing was established that removed the registered nurse from direct patient care and positioned the registered nurse in a management position over licensed practical nurses (LPN) that were trained in just one year with a technical function (Calalano, 2006). This practice continues today with the registered nurses given the title of charge nurse with the responsibility to supervise all nursing care within a unit for the eight or twelve hour shift. The charge nurse is in the management position over the nursing unit and is responsible for communicating directly with the physicians for any changes in patient status or care.

\section{Nursing Education and Post World War II}

The post World War II nursing shortage is attributed to the poor working conditions and low pay, as the salary for a staff nurse in 1946 was about $\$ 36.00$ a week; well below the compensation for secretarial positions and far below what the average male salary (Joel, 2003). This nursing shortage was filled with nonprofessional positions created to help in patient care: licensed practical nurse, nurse's aides and orderlies. There were also recruitment drives and reeducation programs for married women, a former taboo in nursing school. Diploma school programs were used at this time to have the nursing students function as a part of the actual nursing staff at the hospitals (Hein, 2001). The associate degree programs and baccalaureate degree programs both qualified for the graduates to take the national licensing board examination which measures the qualification of the graduate. By 1965, the associate degree prepared nurses outnumbered the baccalaureate degree prepared nurses; in response to the concern about the lack of professionalism in the practicing associate degree nurses, baccalaureate degree programs and graduate level programs were increased (Catalano, 2006). 
The evolution of nursing as a profession has been in process as the scope of nursing practice has expanded (Catalano, 2006). There has been concern that the expansion of the technical skills that is encouraged and supported to foster professionalism results in the nurse delivering functional nursing care instead of the patient centered care (Angrist, 1965).

Historically, professionals have been associated with universities involving high levels of study, including scholarly research (Joel, 2003). Early research studies focused on the development of professionalism in graduate nurses or nursing students in baccalaureate degree programs (Feltzer, 2003). Hanks (2008) states that professional traits such as autonomy are developed by the nurses during a longer education experience, such as a four-year program. More recent studies included associate degree graduate nurses with the interest generated by the nursing shortage and the nursing educator shortage. It is believed that this may be an untapped source and should not be discounted because they are graduates of an associate degree program (Logan \& Jones, 2008). Nursing professionalism is perceived as an inductive process and the majority of the studies concentrated on the development of professionalism in graduate nurses or baccalaureate degree nursing students without consideration of associate degree nursing students (Cook, Gilmer \& Bess, 2003).

\section{Development of Nursing Curriculum}

The early diploma nursing programs during the first part of the nineteenth century provided no formal preparation for nursing but trained young women in the apprenticeship type of schooling by working in the hospitals (Joel, 2003). There are $25 \%$ of current registered nurses who attended diploma schools, which do not provide a nursing degree to the graduates. The number of diploma schools has been declining over the last forty years (Raines \& Taglaireni, 2008). The design of the programs include a relationship between the diploma program and a 
hospital where the clinical experiences are held, the students are well prepared to function in that particular setting, but are not limited to it. Curriculum for these programs includes general education in the sciences plus nursing theory and practice and the standards and competencies of the diploma program is regulated by the National League for Nursing Council of Diploma Programs (Zerwekh \& Claborn, 2006).

\section{Baccalaureate nursing}

The baccalaureate degree nursing programs are offered at colleges and universities and the curriculum for the baccalaureate degree student includes a higher level of physical and social sciences, public health, community health, nursing research and evidenced based practice, management and humanities. There are over $30 \%$ of current registered nurses that are graduates of the baccalaureate degree nursing programs (Raines \& Taglaireni, 2008).

\section{Two-year associate degree nursing programs}

The education preparation in the associate degree nursing programs is usually done at a community college level, but is not restricted to that format. The student must complete general educational and science course requirements. The associate degree nursing programs attract a diverse student population of older students, married students, and minorities (Zerwekh \& Claborn, 2006). These nursing programs are the most economical approach to a registered nursing degree and $42 \%$ of the current registered nurses attained their education in this manner. The curriculum for the associate degree nursing programs encompasses the intellectual and clinical practicum experiences necessary to function in a variety of nursing settings. The National Organization for Associate Degree Nursing is active in promoting associate degree programs (Raines \& Taglaireni, 2008). 
Just what makes a registered nurse so important in the health care experience? Nurses play an important role in healthcare delivery and the nursing shortage has actually served to accentuate the role of the registered nurse. Current research substantiates what many patients have known from personal experience, that too few nurses result in a decrease in the quality of care delivered. The expected need for more than 500,000 nurses in the next 15 years demonstrates the great need for new recruits. Nursing has become a good avenue for those wishing to change careers and to all of those people desiring to make a difference in the lives of others. The increasing prospects and salary incentives makes nursing an attractive career option (Raines \& Taglaireni, 2008).

\section{Current Public Perceptions and the Impact on the Nursing Shortage}

Who wants to be a nurse? Social and cultural changes slowly progress and the public perception of the registered nurse is closely to social and cultural views. The role of the nurse is tied to the completion of tasks, in the public's view, and does not consider critical thinking or problem solving abilities to be part of the professional requirements. The role of the nurse is associated closely with the physician and is not viewed as a role of independent thinker and extension of health care service (Hein, 2001). This view negatively influenced highly motivated intelligent students from considering registered nursing as a career and resulted in a decreased number of potential nurses. In the nineteenth century, the male dominated medical profession was wrestling control of the hospitals from the church or community members who maintained authority over the hospitals. When the physicians were successful in becoming the controlling authority within the hospitals, there were territorial concerns that nurses would usurp the medical authority and this resulted in a concentrated, focus movement against allowing the nurses to gain any shared status with physicians. Promoted as what was safest for the patient and for the weak 
minded female nurse, the medical establishment prevented the female nurses from entering any part of the domain of medical knowledge (Gardner, 2005).

The media has a strong influence on the view with which nurses are identified by the public with the publication of newspaper and magazine articles which add nurses to stories of healthcare only as incidental. There is an overwhelming portrayal of nurses as female, white, middle class and blonde with no nurse aged more than 35 years of age (Zerwekh \& Claborn, 2006). Public perception of storybook themes associated with registered nursing includes the public image of a born nurse, as the road to marriage (presumably a physician), and as a physician's helpmate. Nursing has long struggled for the public to understand that nursing is a separate and distinct profession and the media, which greatly influences the public, has not helped. It has projected the concept that the nurse is subordinate to the physician and the public failure to recognize this inaccuracy has greatly damaged the image of nursing (Hein, 2001) and is another factor in making the choice to become a registered nurse an unattractive option. The power of mass media must be recognized for the strength of influence. In an investigation, the Kelsey Family Foundation (1997) discovered that one episode of the television program ER, in which contraceptive practices for post intercourse were used following date rape in the story line, resulted in an almost twenty percent increase in viewers knowledge concerning this use of contraceptives by the next day, although the segment was only a few minutes of air time. The examination of children's programming demonstrates the nurse as being a helpmate to the physician or the nurse as someone who is not even mentioned (Gardner, 2005), evidence that children are learning who does not want to be a nurse. 


\section{Contexts of the nursing profession}

\section{An exploration of current issues}

The tightened budgets of healthcare providers have affected many levels of healthcare. The cuts made in nursing staffs have resulted in a shortage of registered nurses. The increasing need for registered nurses has forced nursing education to examine how nursing curriculum addresses the development of nursing professionalism in the graduates. The nursing shortage is usually realized for most people when either they or someone they love have a hospital experience. This can be inpatient or outpatient services. It is easy to believe that the shortage of nurses being experienced is a result of someone that should be there isn't because of illness or something that has kept them from working. It is only through the media that most people learn that the nursing shortage is a national problem for this country. The aging population in the United States is leading to a large number of retirements throughout professions and jobs. The nursing shortage, however, makes the impending retirements of nurses a crisis for healthcare. Without adequate numbers to withstand such a loss, registered nurses will be fewer than ever to provide care. Complicating the picture further is the lack of professional guidance available that are so beneficial to newly graduated registered nurses (Blakeley \& Ribeiro, 2008). The establishment of managed care in the late 1990s, during which reimbursement for health care services was achieved through cost management guidelines, has contributed to the current nursing shortage. The dynamics of cost tightening caused health care facilities to downsize, administrative salaries to decrease, and registered nurses to be removed and replaced with unlicensed assistive personnel at lower salaries. There was also an absence of nursing recruitment efforts to the public from 1998-2002 (Allen, 2008) signifying an underestimation of the importance of registered nurses in health care delivery. Hospitals dismantled their 
departments of nursing in response to the pressure from health care insurers and government. Nurses were expected to support and champion the new process of shortened hospital stays and increasing numbers of outpatient procedures and surgery, all resulting in patients being discharged to home earlier in their recuperation period than previous standards allowed. Nurses failed to believe that this method was beneficial to the patient and then began to question their role in nursing altogether (Gardner, 2005). Health care shortages are not unique to the United States. In England, the government estimation of gaining over 3,000 school nurses by 2010 is not becoming a reality and the plan of a qualified school nurse for each section of primary and secondary schools developed in 2004 has failed. In addition to being a registered nurse for this position, the nurse must have school nurse qualification, again reflecting fewer registered nurses to continue the education to gain the certification necessary (Blakemore \& Doult, 2009).

Educational preparation for registered nurses in this country can be accomplished through a variety of programs such as diploma nursing programs, associate degree nursing programs, and degree nursing programs. Regardless of the educational path, each nursing school graduate of diploma programs, associate degree nursing programs and baccalaureate degree nursing programs is eligible to take the National Council Licensing Examination for Registered Nurses board examination for licensure. This certification is attained by demonstrating minimal competency on the examination, providing the public with protection that the nurse is competent (Zerwekh \& Claborn, 2006). Regardless of the type of nursing degree, the program must be certified by a nationally recognized accreditation body, either the Commission on Collegiate Nursing Education (CCNE) or the National League for Nursing Accrediting Commission (NLNAC) (Raines \& Taglaireni, 2008). The accreditation body uses predetermined standards and outcomes in a peer review of the nursing program. The National League for Nursing 
Accrediting Commission is the organization which accredits all levels of nursing programs (Zerwekh \& Claborn, 2006).

Nurse educators are responsible for preparing registered nurses who will function with professional standards and respond to the increasing healthcare needs of society with quality patient care. There are decreasing numbers of nurse educators and this problem is expected to worsen within the next several years. It is estimated that almost 300 doctorate prepared nurse educators and approximately 280 masters prepared nurse educators will be eligible for retirement within the next decade (Foxall, Megel, Grigsby, and Billings, 2007). Their study found that almost half of prospective retirees would continue working if there was part time work available, if there was fair salary with adequate benefits, if there was intellectual stimulation, and a positive, supportive work environment. The idea of flexible scheduling was a major incentive to continue working. After retirement, nursing educators do not return to the academic setting with a further loss of expertise and increase in the shortage of nurses.

\section{Technical Changes for Nursing Curriculum}

The increasing popularity of online nursing programs is viewed as a viable option to counteract the onslaught of the nursing shortage, but at what cost to nursing? Nursing education traditionally teaches the components of critical thinking, teacher-student interactions and expressing and documenting content specific to nursing. The absence of nursing research to investigate online assignments for evidence of these components (Carter \& Ruklom, 2008) results in a delivery of content that is without validity in nursing specifically. Registered nurses participating in an online research project had their discussion postings studied for the four areas of knowing in nursing, empirical, ethical personal, and aesthetic. The authors found that the participants considered empirical knowing as more important than the other types of knowing 
(Carter \& Rukholm, 2008). The other three realms of knowing, essential for quality patient care, were absent. In a web based delivery of university nursing curriculum from twenty years ago, the students completed selected courses in the conversion from traditional format to an online classroom. The students described what they liked best about the experience and expressed feelings of convenience, group process, enjoyment of writing, threaded discussions, lack of travel, and family help. The authors evaluated this as a successful transition of curriculum (Zucker \& Asselin, 1989). Missing, of course, are any indications of experience of the patterns of knowing, essential for the wellbeing of the patient.

The ethical component of nursing knowing is attached to what each person feels is right and just. The ethical standards of nursing students and increasing impact of technology on nursing education were explored by Arhin (2009) in studying the student perception of academic dishonesty. Dishonest behavior during testing was recognized by the majority of nursing students in the study. These nursing students recognized cheating as looking at notes or having hidden notes but had problems identifying dishonest actions in using another student's work, with that student's permission. The nursing students felt it was dishonest to use another student's work without that student's permission. Nursing students felt that cutting and pasting from an online source without designating that source was not dishonest. A study examining ethical reasoning in nursing students in a baccalaureate degree program found that the incidence of ethical dilemmas in nursing is increasing. The ability of the nursing student to develop ethical decision making choices as a result of a developmental process was enhanced by written reflections and self examination by the students. This development aided the nursing student to have confidence in standing up for ethical principles in personal and professional roles (Callister, et al, 2009). This exercise may help nursing students choose the ethical choice when confronted with academic 
dilemmas. The study by Arkin (2009) found that nursing students had more difficulty in identifying dishonesty in laboratory settings, although most felt that fabricating laboratory experiment results was dishonest. The availability of online resources and technological abilities are changing. The availability of technology and the acceptance of dishonest behavior among peers demonstrate the essential need for the ethical knowing component in nursing education without regard to the format delivery of the content.

There are external and internal issues which continue to affect nursing and they are intertwined. The external factor of a worldwide nursing shortage, which includes registered nurses and nursing educators, threatens to again affect policies and educational efforts to meet the needs of the public but without concern for the needs of nurses. In the past, this has generated changes in nursing education, such as the development of associate degree nursing programs, for which the American Nurses Association, concerned with the scope of nursing practice and the quality of education, has positioned that the baccalaureate level nursing degree should be the entry level degree for registered nurses. This position transfers the external factor into an internal issue within nursing, and that is education which is dynamically connected to the development of professionalism in nursing. The investigation into the development of nursing professional should include all educational levels and this researcher seeks to explore the development of professionalism within associate degree nursing programs.

\section{Implications for nursing education}

Nursing most certainly can be promoted with positive effects as seen with the Johnson \& Johnson media campaigns (Allen, 2008) to communicate the many facets of nursing care and highlight the men and women who dedicate their energy and time to care for patients in a variety of health care settings. By 2004, the Johnson \& Johnson campaign was perceived by the public 
as communicating a positive image of nursing (Buerhaus, Donelan, Ulrich, Norman \& Dittus, 2006). In addition to this national effort on behalf of Johnson and Johnson, registered nurses themselves must make an effort to promote the face of nursing. Registered nurses can positively promote nursing within their own communities by doing blood pressure screenings and health education. Career days in local high schools and middle schools are another possibility available as are community fairs and festivals. Registered nurses have the power to promote nursing within their place of employment. Always introduce yourself as a registered nurse to staff and patients, wear the RN name tag proudly so it can be seen. Many hospitals have instituted message boards within the patient's rooms so that each patient knows who is providing their care for that shift; make sure your name includes the RN designation. In addition to presenting a professionals appearance, it is important to function in a professional manner. If you have complaints or personal matters, be mindful of who is listening and never discuss them within a patient's hearing. An example would be when a patient is experiencing some unpleasant event, such as urinary incontinence. The patient may already feel anxiety and embarrassment about the incontinence, but hearing a nurse complain about changing the linens multiple times for the patient causes the patient to feel shame and widespread embarrassment.

Colleges and universities can also increase nursing recruits by rethinking what they are doing. Changes in existing programs such as admitting nursing applicants more than one time a year can begin accepting students every six months. Traditionally, nursing classes are during the day and this can interfere with potential nursing students who work; nursing didactic curriculum can be offered in the evening, with the clinical component at a hospital or facility during an afternoon shift. College classes can also be delivered either in the hospitals or within close proximity in an effort to attract people who are already in health care who have the desire to 
become a registered nurse. Getting a registered nursing degree online sounds attractive but nursing classes cannot be indiscriminately transferred to online classes. Thoughtful choices can be made for the adaptation of some courses but these decisions should be made with the full contribution of nursing administrators and nursing faculty within the college considering creating online nursing courses. There is a striking difference between simulating care for a virtual case of a patient with a decreasing blood pressure, heart rate and level of consciousness and experiencing the same situation in reality. In addition to the dynamics of the patient, including the fear of dying, the clinical environment may be challenging as the nurse must deal with family members, other healthcare personnel such as nurses, physicians, respiratory therapists and nurses aids.

The relationship between the perceived support of nursing faculty by graduating nursing students, nursing students who did not successfully complete the program for a reason other than inadequate academic performance, and nursing students who were not successful academically and were no longer students has been established. The nursing students in their last semester of nursing school expressed the highest perception of nursing faculty support while the students who were not successful academically and were no longer in the program expressed the lowest perception of faculty support (Shelton, 2003). The significance of a caring, demonstrative nursing educator is realized in the academic success of students receiving assistance and encouragement. The students who are beginning to struggling academically, financially or socially should receive support and assistance available before they become overwhelmed, before it is too late to recover and be successful. Even one nursing student success is a cause for celebration (Hopkins, 2008) and a strike against the nursing shortage. Students should be encouraged to participate in nursing student study groups and to pre-read the nursing content 
before it is presented and discussed in the classroom. Reading articles in nursing journals and publications pertinent to the content being covered often provides the student with another perspective on the content, which enhances capture and understanding of the concepts. Higher education must also look to actively recruit nursing educators from promising graduating nursing students in the college or university setting. Nursing educators can serve as mentors for these graduates as they step out into the profession. Experience in nursing practice is essential to becoming an effective nursing educator and the nurse educator can offer encouragement and support throughout this process to the developing nurse educator. When I became a nursing instructor, my nursing experience included medical surgical and intensive care unit experience, neither of which prepared me for teaching; it only provided me the potential to teach. It was the efforts of two experienced nursing instructors who nurtured and supported me throughout my learning process. There was always someone who could give me guidance or answer a question and I never felt alone. This allowed me to grow and develop into an experienced nursing instructor who can now help new instructors.

College administrators should provide compensation to the nurse educators to function as mentors for these potential nurse educators. Retirement for nursing faculty can be slowed by communicating to them how valuable they are to nursing education and demonstrating that worth by flexibility in scheduling, hours, and salary and health care benefits. They may serve as consultants after retirement as their experience and expertise in teaching far surpasses those members of faculty that are just beginning. The consultant faculty member could be designated as a mentor for a newer faculty recruit promoting feelings of worth in helping the newer instructor and the newer faculty member feeling supported with higher levels of confidence because of the nurturing and support. 
We must be careful to adequately prepare nursing students to develop into caring nurses who provide patient care at a quality level, even during a crisis period with a nursing shortage. Nursing education cannot be compromised in the mission of preparing the nursing student to become a compassionate, proficient nurse. Current nursing practice is based upon research based care, called evidenced based practice. The practice is based upon scientific research that has shown it to be advantageous to the patient with effective, predictable and measurable practice outcomes. Evidenced based practice utilizes not only nursing knowledge, but knowledge from other disciplines, such as medical research and social research (Zerwekh \& Claborn, 2006). Nursing education must maintain the highest standards of curriculum and delivery, regardless of what is happening socially and economically in the world. The focus on the national nursing shortage has increased salaries and there are increasing opportunities available for the registered nurse. It has also demonstrated the critical role that the registered nurse fills in health care delivery. Registered nurses are an integral part of overall quality of care and patient safety. There has been a five percent increase in 2006-2007 in the number of nursing students in programs in the nursing schools in this country. The projected job growth for nursing is estimated at 587,000 new nursing positions through 2016 (Raines \& Taglaireni, 2008). As Florence Nightingale believed that the patterns of knowing in nursing must be an integral part of nursing education, so it is today. These patterns must be consciously promoted within each didactic and clinical course in nursing education. The empiric knowing can be included in the pathophysiology didactic courses with the conscious application of science applied into reality of patient experience. Registered nurses intertwine empiric knowledge and personal experience with multiple levels of awareness in the application of that knowledge (Bonis, 2009) thus making each nursing act unique to that patient and that nurse. The ethic knowing should be an active part of each course; 
we know that the perception of what is right and what is wrong is essential to registered nursing. Students must understand that it is the right thing to do when they refuse to participate in any cheating that is available and they make that choice not out of fear but from the ethical understanding they have of the situation. Knowing in nursing is specific for each nurse and based upon the experience and self study of each person. The nurse makes meaning of knowing and transforms the person into the nurse (Bonis, 2009). Personal knowing can be developed and realized through journaling and self evaluation exercises. Case studies in which the student can apply empathy can then be followed by clinical experiences which promote the same. Nurses are better equipped to understand the patient experience and be in the moment with the patient through awareness and contemplation which then allows the nurse to plan therapeutic interventions for the patient (Bonis, 2009). Aesthetic knowing is a cumulative process for development and should be present during the later phases of student growth. The educational process should encourage the search for aesthetic knowing and the identification and encouragement of nursing experience that demonstrates the nursing student bringing meaning to the patient experience. The ongoing process of transformation involving knowing, understanding, awareness, making meaning contributes to a deeper understanding of knowledge and improvement of the nursing practice (Bonis, 2009).

The Radwin Research Study (1998) examined the relationship between nursing knowing and clinical decision making among baccalaureate prepared nurses in a Massachusetts study. Knowing the patient was the foundation for clinical decision making using the nurses' knowing combined to consider the patient's condition and three attributes emerged in the study. Nursing experience allowed the nurse to focus on the patient and patient needs; the nurse was less likely to focus on self and was successful on integrating the patient experience of illness, treatment, and 
perceptions for quality care. Nurses with experience were better able to be in the moment with the patient and consider the patient's feelings and perceptions and deal effectively with sad and sorrowful expressions of the patient resulting in meeting the patient's needs. Nursing experience also aided the nurse in applying empirical knowledge of past patient experiences to the current patient situation resulting in better understanding of treatments and outcomes.

The shortage of registered nurses has been experienced throughout history and the current shortage may be a continuation of almost twenty year transformation in health care practices. It is the reaction to that shortage that we must examine carefully. Nursing education must be vigilant. Altering existing standards of education and curriculum to allow less than adequately prepared registered nurses would have a far-reaching negative effect on the care of patients as well as the nursing profession. Nursing education must enable the nursing students to develop critical thinking abilities. This development of complex thinking patterns demonstrates the importance of formal instruction and planned practice (Raines \& Taglaireni, 2008). The unsuccessful attempt in the 1990s to replace the most expensive personnel, registered nurses, with lesser paid unlicensed patient care technicians resulted in short term decreased savings but had long reaching effects on decreasing quality of care. Hospitals are realizing the effects of that attempt now, in reduction in the number of patients at these facilities and the closing of hospital units (Catalano, 2006). We cannot afford to make the same mistake. Florence Nightingale lamented that using the word nursing failed to encompass what the act of nursing actually is, suggesting nursing is only medication administration and the dressing of wounds (Nightingale, 1969). The image of nursing is closely tied to the treatment of nurses and we must be aware of that fact. Registered nurses must speak positively of their profession and encourage others by word and example to join the profession. Nurse educators must remember that teaching is 
guiding that student in taking that educational content into a deep, rich analysis and interaction with the moment, the environment, the experience and the patient. The shortage of registered nurses is a current reality and the history of nursing demonstrates how the implications and power of the decisions and actions of today will establish the reality of the future for registered nurses and the profession of nursing.

\section{Curriculum and the Development of Nursing Professionalism}

In a study to understand how professionalism of associate degree nurses begins and develops, Feltzer (2003) stated that professionalism has primarily been promoted through education at the baccalaureate degree nursing program level yet associate degree nurses are half the work force. The study supported that self-actualization is related to professionalism, and demonstrated that the higher the perceived self-actualization, the higher the degree of professionalism. Feltzer surveyed the alumni of four associate degree nursing programs in the northeastern United States. Limitations of the study included the small geographical area and the lack of different ethnic backgrounds for the nurses. This study demonstrated the existence and development of professionalism in associate degree nurses. It supported the need to address professionalism development in the associate degree nursing programs (Fetzer, 2003).

Manninen (1998) conducted a longitudinal study of Finnish nursing students to determine the view of nursing by nursing students. The development of nursing science has shifted nursing education approach to a human scientific model, away from the traditional role of nursing education toward professionalism. The purpose of the study was to determine how students gain understanding of nursing through education. The study compared differences between groups of students in specialty nursing areas of medical surgical nursing, psychiatric nursing, anesthetic and operating room nursing, pediatric nursing, and public health nursing and midwifery. 
The results of the study demonstrated that students emphasized well being and health promotion as attributes of nursing throughout their nursing education. Students perceived nursing professionalism strongest at the final stage of education. The findings supported that professionalism in nursing is developed during the educational experience. The findings also supported that the development of professionalism is accomplished based on a nursing model and can be encouraged by the curriculum of a nursing program (Manninem, 1998).

Professional ethics are a professional trait in nursing and Thorpe \& Loo (2003) identified the problem of the absence of an established profile of values necessary to nursing practice. The purpose of the quantitative study was to identify values with attention to those values considered important to nursing undergraduate students. The study sample was from a Canadian university with volunteer undergraduate students with majors in either nursing or management. The results of the study supported occupational and sex type stereotypes associated with the nursing profession, with recognition of the high value assigned to altruism and professionalism. Recommendations for educators included having nursing students focus on values as a selfdiscovery process early in the educational process. Also, information should be provided to the students about life and work values, with class discussion and optional readings included. Skills training related to risk, creativity and critical thinking will ensure students enter the nursing profession with professional level skills, which encourage them to think about more effective and creative ways of delivering nursing care. This study focused on undergraduate nursing students and explored the values determined as important for professionalism and supported the introduction of these values into nursing education (Thorpe \& Loo, 2003).

Nursing students must be prepared to address moral issues about their patients and make informed choices, which have been based on conceptual frameworks of nursing. The associate 
degree in nursing students were in the first semester of the program and the baccalaureate degree nursing students were in their final semester of the program, there were also second career nursing students in the study. This allowed questions about the educational levels within the program in the two questionnaires each participate completed. Recommendations included faculty becoming knowledgeable about the ethics of justice and ethics of care reasoning. This study examined the moral reasoning abilities of nursing students, a concept that is included in the synthesis of the nursing student in the development of professionalism (Wilson, 1999).

The ethical code by which a registered nurse is expected to abide is expected to be demonstrated by the student in nursing school. Honesty is imperative to trust and trust is essential in nursing; medication administration depends upon the ethical behavior of the nurses to select the correct patient, medication, dosage, route and time. Any alteration along this pathway compromises the quality of patient care. The majority of students within the college classrooms are members of the generation of which technology has proliferated with the resulting internet, cell phones and iPods, all of which allow for instant messaging. This same technology allows for academic cheating, which is especially troubling for nursing students. Students perceive dishonest behavior during testing as someone writing notes on their body or going to the restroom to view hidden notes but have problems understanding that plagiarism from a fellow student or from a formal source, including the internet, is wrong. Students perceived dishonest behavior during laboratory testing, such as fabricating results, but had trouble deciding it was wrong to get help from another student during the same testing period. The authors of the study contend that the most effective method to reduce academic dishonesty is to put into practice the prevention of cheating (Arhin, 2009). 
A study which explored the beliefs and concepts about nursing at a very early stage of educational development was explored in a university setting. The problem addressed in this study was that nursing identity is the foundation of nursing professionalism, so nursing faculty are interested in how students perceive and define professional identity. This study supported the importance of education in the development of nursing professionalism. The assessment of the student definition of professional identity is the basis upon which the development of professionalism in nursing can be built (Cook, Gilmer \& Bess, 2003).

The research demonstrated the prevailing concept that professionalism was an inductive process within the professional education of the nursing student. In the earlier studies, the associate degree nurse with only a two-year program of study was not included. Later studies addressed the associate degree graduate nurse, but the studies focusing on associate degree nursing students are still lacking. There is a gap in the literature addressing how nursing professionalism is developed during a two-year associate degree nursing program. It is important to determine when the growth of professionalism actually develops because the level of professionalism has a positive effect on patient care.

The contribution that education plays in the promotion of the development of professionalism in nursing is examined in a study comparing online nursing degree and associate nursing degree nursing students addressing ethical dilemmas. This study examined the contribution to nursing as a profession by integrating the values into nursing clinical practice and found that the associate degree students scored higher in privacy, accountability, judgment, implementation, and collaboration and the implications were for all nursing faculty to realize that students experience growth as professionals at different rates (Martin, Yarbrough \& Alfred, 2003). Values are an essential part of nursing professionalism and are defined as core values of 
altruism, autonomy, human dignity, integrity and social justice. The ability to apply these values into nursing practice promotes the development of professionalism and was demonstrated by a study on a nursing program in which there are first generation, minority, low socioeconomic status. Altruism was introduced through sharing of stories of when the teacher and students were patients and autonomy was introduced with a film followed by discussion and patient care, which involves actions that might differ from the nurse. Human dignity was introduced as a workshop with group activity; integrity was introduced as a film followed by discussion with abstract concepts taken into a clinical setting, and social justice was introduced by students learning about health care inequalities for specific people and discussions about social policy. It is necessary to address the introduction and encouragement of these values in new, exciting and continuous teachings (Shaw \& Degazon, 2008).

The value of mentorship is examined in a study by Ronsten, Anderson \& Gustafsson (2005) in which it was concluded that the registered nurses' experience in nursing practice is directly related to the development of professionalism through self confidence and quality care; a positive practice experience contributes to the development of nursing professionalism. The novice nurse's continuous reflective practice helped foster professionalism and a holistic nursing concept. Motivation was experienced by the mentor and mentee and the study proposes that the increased competency beliefs may empower female nurses in pay and career advancements. The dialectical nature of discussion is examined in a study by Platzor, Blake, \& Ashford (2000) where they examine the value of viewing clinical situations from various perspectives and brainstorming different alternatives allowing the students to develop critical thinking skills and professionalism. The facilitators of the discussion groups did not present any structure but asked that students focus on their own experiences in any role in nursing and nursing teaching. The 
results of this exercise encouraged critical thinking skills and the understanding of the views of others.

Nursing education must address the existence and power of shame, which contributes to the oppressed behaviors of hostility toward each other. Shame feelings cause a sense of withdrawal from the shame making situation and can be associated with power strategy, with the educator the oppressor and the student the oppressed. Humiliation is a strategy used by an individual or group to gain power over another; when a person feels shame, they also feel guilty and anxiety has a strong role in this process. This concept is important in education because the high anxiety levels associated in these power situations impair learning because the student is so self-focused. This impairment of learning has a direct negative effect on patient care when it is transferred into the clinical setting. Shame also interrupts the development of professionalism in nursing because it impedes the socialization that accompanies it. Students who are able to connect rationally with their instructors, without anxiety and the resulting humiliation and shame, develop the concepts of organization, communication and competent nursing skills, responding to the ever changing needs of the patient. The concept of shame is not well documented in nursing literature and this study was done by a nurse who experienced shame during her time in nursing school (Bond, 2009).

\section{Nursing Curriculum and Professional Standards}

Nursing education endangers the profession of nursing if all nurses are not held to a professional standard. This directly relates to the development of professionalism in all levels of registered nursing programs. The professional image of nursing is promoted by the professional appearance, behavior, communication abilities and dress of the nurse. For the benefit of nurses, patients and the public, the nurse must reflect professionalism in appearance and behaviors. 
These are also areas of development encouraged by education with nursing faculty modeling professional behaviors and teaching the traits of professionalism (LaSala \& Nelson, 2005). Teaching in nursing is complex and requires the art as well as the science of nursing with application into the clinical practicum. There is educator responsibility related to curriculum development, teaching, learning and evaluation of student learning outcomes. This is coupled with professional practice competencies and the responsibilities normally related to students, faculty and college governance. The nurse educator must accomplish teaching, scholarship and service. The origin of nursing education started with Florence Nightingale and has evolved with the needs of society. Educational philosophies upon which the curriculum is based include John Dewey's belief in deliberate curriculum development and revision (Billings \& Halstead, 1998).

Effective teaching in nursing today encompasses many different behaviors and traits and must consider the personal experience and consciousness of each individual student to enable the student to grasp and make meaning of the knowledge. Professional competence in nursing education includes enthusiasm for nursing and nursing education, a visible interest in patient care, and confidence in self skills. The educator must be able to develop interpersonal relationships with students by demonstrating an interest in student learning, sensitivity to their problems, communicating respect, and being fair.

Freire (2007) states that learners build meaningful series of themes based upon the student's relationship with the world and reference to known facts. The curriculum that encourages the student to make connections between the themes aids in the student taking in the content, making meaning and promoting deeper understanding. The learner filters all learning through their own personal historical and cultural themes unique to each individual. Evaluation of the teaching methods is essential for a nursing educator, including updating material to reflect 
changes in knowledge, research, technology and resources. Nursing educators, probably more than any other, must be available to the student, whether it is classroom or clinical setting. The nurse educator must also teach the nurse to teach, as the nurse will be responsible for teaching as a major accountability for registered nurses.

The nurse educator who demonstrates sound nursing knowledge, clinical skills and judgment serves as a model of professionalism to the nursing student (DeYoung, 2003). The American Association of Colleges of Nursing define the associate degree registered nurse as a nurse functioning at the bedside of less involved, less ill patient care setting. The American Association of Colleges of Nursing maintains that maintenance of a tier of professional nurses of diploma school prepared nurses, associate degree nurses, and baccalaureate degree nurses will help alleviate the current nursing shortage. Nursing education continues to be hotly debated. A four year college or university degree is standard for most professions and a requirement for all other health care clinicians other than physicians (Gordon, 2005). How can nursing legitimately realize establishment as a profession when the educational requirements for registered nurse have so much variation? 


\section{Chapter III}

This chapter explores the quantitative and qualitative methods of the study. The multitechniques methods included the survey tool, the Registered Nursing Attitude Scale, administered to associate degree nursing students at two separate times: the first at pre-nursing school status and the second at post-nursing school status. The interviews with registered nurses explored the experiences of nursing reality in large, urban health models and smaller, rural health models. The focus group of nurse educators provided the insight of how these educators believe they are preparing the nursing students for success and for promotion of nursing professionalism. The reader is guided through the gathering of data affecting views of the registered nurse in the phases of before they were nurses, while they are nurses, and while they are teaching nurses so it is a unique look at a full cycle of registered nursing.

\section{Methods}

This research utilized multiple techniques to answer the question: What is the influence of nursing curriculum in associate degree nursing programs on the development of nursing professionalism in graduating nursing students? First, using a survey administered to nursing students in the Registered Nursing program at a Community College Associate Degree Program $(n=216)$ in West Virginia. The qualitative survey tool was developed using the professional standards of nursing professionalism as defined in the nursing literature. The research tool is based upon assessing the dimensions of nursing professionalism as perceived by the nursing student using nine statements communicating registered nursing traits and behaviors as defined by the American Nurses Association (Zerwekh \& Claborn, 2006). It is scored by the registered nursing student from one to five; with strongly agree to strongly disagree. The survey tool also assessed the work history as a nursing assistant for the nursing student, the age and gender of the 
student, and the years of college education completed. The survey tool was developed based on the traits of nursing professionalism with each survey statement corresponding to an assessment of a trait of professionalism and seeks to count the degree to which the variables of nursing professionalism, educational level, and nursing experience are present (Macnee, 2004). The survey tool was designed as a questionnaire because most people are familiar with that format and can decrease anxiety for the nursing student completing the form and increase the likelihood of effectively completing the tool. The questionnaire also prevented the researcher's opinions from influencing answers, something more likely in interviewing the students as this researcher has power and strong influence as a nursing instructor in that institution. There was little flexibility in the answers on the survey tool and it prevents any student from elaborating on their answers, a definite disadvantage. The one page design was intended to hold the interest of the study participant. Ease in completing and submitting the survey tool was facilitated by the distribution, time allowed for completion, and collection of completed surveys in the room.

The sample of 216 nursing students included 182 female students and 34 male students. Some type of formal education was experienced by 128 of the females, with 54 having no formal education, and 14 of the males experiencing some level of formal education with 20 having no formal education. This resulted in seventy percent of the females having some formal education and forty percent of the males having some formal education at the time of their entry into the Community College Nursing Program. Permission to conduct the study was obtained from President of the Community College. Students were guaranteed anonymity by the researcher with names on survey tools being used to match pre-nursing school perceptions to post-nursing school perceptions to the same nursing student and then names will be replaced with numbers only (See Appendix A). 
Second, four in-depth interviews were conducted. The first interview was with a registered nurse working in a large, urban hospital to represent a major health model. The second interview was with a registered nurse working in a small, rural hospital to represent a smaller health model. The third and fourth interviews were conducted with registered nurses who participated in this research study when they were nursing students. The methods used for these interviews are those defined by Polit \& Hungler in Nursing Research: Principles and Methods (1995) and Norwood in Research Strategies for Advanced Practice Nurses (2000). The interviews will be guided by the following questions:

How do power relationships affect the role of the nurse?

Is there an impetus to further your nursing degree?

What happens to the status of the nurses during a nursing shortage?

These questions or talking points seek to add a qualitative dimension to the survey. Given that most of our graduates work in these two distinct types of settings, the interviews provided a work context that may guide the future work of our graduates. When combined with the survey answers, the researcher explored if the survey results matched the perceptions and realities of those working in the field. The key connections revolve around the idea of the role of identity in the profession and its impact on both practice and education.

The third technique used in this research was data collection from a nursing educator focus group, which met to discuss nursing education. The researcher used techniques as described by Polit \& Hungler in Nursing Research: Principles and Methods (1995) to guide the discussion. Given the importance of education to professionalism in nursing, it is crucial we interviewed those that deliver the curriculum. The focus group served as the third part of a triangulation that gave a second qualitative dimension to the survey. The researcher examined the experiences of 
the surveyed students through the eyes of educators. This focus group attempted to address the following topics:

How do educators define professionalism?

What is the most important thing that students feel they need to learn?

Does this conflict with what you, as an educator, feel is most important?

Do you prepare your students differently for working in a large urban hospital as you do for a small rural hospital?

The data collection from the student surveys, the registered nurse interviews, and the educators' focus group were examined for like-themes of the research premise. This type of research is couched in the idea that structural change only occurs when multiple perspectives are explored simultaneously around similar issues. In this study, the researcher offers an alternative approach to research that enhances possibilities to increase the advantages of qualitative and quantitative research to affect and influence educational policy in nursing education. The process includes all stakeholders in the success of nursing to enhance their social, economic, and political sustainability. In the world of educational change, dominated by educational consultants and reformers, nursing should look inward to establish a vision for change that is created through a dialogue among all stakeholders, and then has the possibility to evolve through an emerging research plan of action for a new form of evaluation. 
Inward Research: inform stakeholders and allow them to be active participants in their curriculum development by understanding those who create, interpret and deliver curriculum.

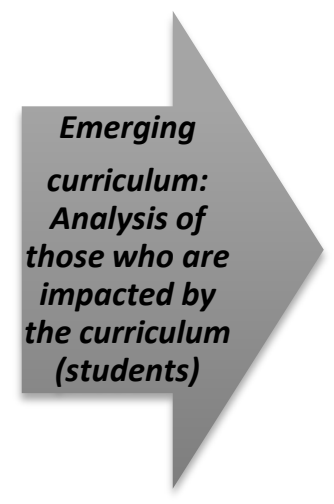

\section{Analyze those who} practice

2. Ebb \& Flow: attempt to connect interviews to specific perceptions emerging from surveys

3. Dialogue and Respect Voices Of Practitioners in determining curriculum

4. Creative Action to address the connections in curirculum that impact nursing professionalism

\section{Procedure}

Quantitative data collection relied on structured instruments administered in classrooms and structured checklists completed by observers. Given the sample sizes examined in the initial phases of this study, the researcher lacked the required statistical power commonly accepted in the Social Sciences $([1-\beta]=0.80)$ for some inferential analyses. Regardless, the researcher implemented inferential designs for replication in subsequent studies. For example, Factorial Analysis of Variance was used to compare responses among: 1) different groups of nursing students, and; 2) different contexts in which education occurs.

Qualitative data was collected through open-ended or semi-structured interviews and field observations of practices (interviews and focus groups). The qualitative data was coded using predetermined templates and grouped into codes, themes, and categories. Quantitative and qualitative data was collected concurrently at roughly the same time during the study. Given time limitations for the research, concurrent approaches that enabled the collection of multiple forms of data at one time was more practical than a sequential approach. Other important considerations included the types of research questions, sampling goals, and the unit of analysis. 
In this project, integration occurred during data analysis, when the qualitative interviews were used to develop a quantitative checklist for the surveys.

Design of the Study

\section{Evaluation of Data}

The intent of this study was to develop an instrument that was grounded in the views of participants (nursing students) rather than use an off-the-shelf instrument that might not reflect their views. Expertise was needed to code and analyze qualitative data, as well as develop a psychometrically sound instrument.

\section{Triangulation of the data}

Triangulation is frequently used in exploratory research, although it is more difficult to implement because of the need to reconcile and bring together numeric (quantitative) and text (qualitative) data. Triangulation is a method recognized in research as a strategy for increasing the significance and truth of the research findings (Hastings, 2000). In this step, the researcher gave equal priority to quantitative and qualitative data and analysis (e.g., observations from courses; surveys from participants; textbook/curriculum analysis; correlations between expectations (pre-surveys) and interviews (practice)). Part of this step was to present the two forms of results as supporting or conflicting evidence for results, transforming one type of data into another form (quantitatively count the codes from qualitative results) to converge results.

\section{Data Transformation}

Data transformation was well suited for this research because it encompassed observational designs such as retrospective studies. This method allowed the researcher to gather qualitative data, analyze it for codes and themes according to a predetermined conceptual framework, and (typically) numerically count the codes and themes. 


\section{Limitations of the Design}

The expertise of the researcher conducting the investigation was an important factor in determining an appropriate type of design. I recognize several limitations in this study. This was my first experience as a researcher in a large, formal research study. My experience as a subject in a large research study in the 1990s influences my view of research studies. My initial educational degree for registered nursing was the associate degree, graduating from the same institution that was the site of my current research, influenced my view of the worth of an associate degree nursing program. My love of nursing and the high standards of nursing care that I believe are the right of all patients influenced my perception. The example that I provided to the nursing students as seeking to advance my educational degree not only affects my interpretations but also the perception of the students who know me. The clinical grading tool for this associate degree nursing program has a section that grades the student's dress, attitude and behavior, attributes all associated with professionalism. The sampling for this study was confined to students in the same associate degree nursing program; much of the perceptions may be learned from the particular instructors and curriculum in this program of my study.

This community college student population has the average age of 30 years and the students are older and wiser than when they may have been of an expected college age, 18 years to 22 years, and are rich in life experience they would have lacked during a younger college experience. The most serious limitation is that the students have chosen nursing as what they want to do, signifying that the role of a registered nurse is a positive role in their mind and these nursing students may score the role of the registered nurse in a more favorable light in completing the survey. The researcher clearly intended to gather and analyze both quantitative and qualitative data in the study. The code for analysis, drawings from the social sciences, was 
modified to better address the nuances of mixed methods investigations unique to this study. The taxonomy should be examined for appropriateness in other disciplines, such as critical care, professional uniqueness, emergency medicine, ethnographic studies, etc. This expansion to other disciplines was particularly germane to the designs the researcher proposed. Additional studies could help researchers not only develop a better understanding of mixed methods approaches used in sustained programs of inquiry but also refine further the criteria for evaluating the quality of health care provided in the field by nurses who participated in the study versus those who do not.

The following chapters are organized in the order of surveys of the student nurses, interviews of registered nurses, and focus group of nursing educators. The intent of including these three groups in the assigned formats is an effort to explore the professionalism of nursing from the student nurses who are experiencing the nursing curriculum which is accredited by the West Virginia Board of Registered Nurses (WVBRN) and the National League for Nursing (NLN). The nursing curriculum content is a result of the collaboration of nursing educators, college educators, college administrators, and the nursing organizations for state and national endorsement. Given the belief by the National League for Nursing (NLN) and the American Nurses Association (ANA) that baccalaureate degree nursing should be the entry level for all registered nurses so the nursing professionalism is established within the practicing body, it is important to explore the view of nursing students who gain their understanding of nursing and nursing practice through the nursing curriculum. 


\section{Chapter IV}

\section{Registered Nursing Attitude Scale}

\section{Introduction}

The results of the survey tool, the Registered Nursing Attitude Scale, are reported with the survey statement first, followed by the results of the $t$-test, to better enlighten the reader of the interpretation of the nursing student. Visualization of the Registered Nursing Attitude Scale is provided in Appendix A. The pre-nursing school response is compared to the post-nursing school response for each of the nine statements on the survey tool. There are four semesters of nursing curriculum experienced by the graduating nursing student from the time the first response was recorded to the time the second response was recorded. The curriculum was provided in the classroom setting and the clinical practicum which was a combined experience of a geriatric center, a psychiatric mental health facility, a pediatric nursing unit, an obstetric nursing unit, medical surgical nursing unit, surgical nursing unit, intermediate care nursing unit, emergency care unit, and critical care nursing unit. There is a visual representation in Table 1 and Table 2. A Factorial Analysis of Variance (ANOVA) examines education and gender followed by life experience, or age, and salary. The community college educates adult students and it is not uncommon for these students to have had an educational life before nursing school so it is important to seek to understand how those experiences affected their perceptions of nursing. Gender is clearly defined within the culture of the community college and culturally assigned gender roles are evident in the actions of the nursing students. How did this affect the nursing student's view of nursing? Visual representation is provided in Table 3. Nursing has been promoted in the media as a good choice for financial stability and healthcare jobs, and in general, nursing is usually on lists of desired fields and job availability for both the present and the future. How does this affect the view of nursing and does life experience change this view? 
The variation in ages within the community college student population provided an opportunity to investigate whether the pay scale becomes more or less important with age. Visual representation is provided in Table 4.

\section{Results}

The Registered Nursing Attitude Scale was used to measure nursing student perception of professionalism in nursing. The scale is a five point Likert Scale consisting of nine items. Responses indicate the extent to which the nursing student agrees or disagrees with statements related to professionalism in registered nurses. Each item is scored on a five point scale ranging from one (strongly disagree) to five (strongly agree). A high score indicated greater perceived professionalism in registered nurses by the nursing student. The data was collected between 2005 and 2008 with 216 completed surveys; 25 surveys could not be used due to incomplete data. The completed surveys signify nursing students who successfully completed the nursing program as their participation was necessary at the start and conclusion of the educational process. The data was analyzed using SPSS for Windows (version 16). Descriptive statistics were used to analyze the demographic variables. Means and standard deviations were calculated for each score of perception. Statistical analysis of Factorial Univariate Analysis of Variance was used to compare the perceptions of professionalism between different demographic groups of nursing students: gender, age, education. Paired Samples Statistics T-Tests were calculated for each of the nine statements for both pre-nursing school and post-nursing school perceptions.

The perception of nursing professionalism in registered nurses as measured by the Registered Nursing Attitude Scale demonstrated an increase in student positive perception during the two year nursing program. A comparison between pre-nursing school perception of professionalism and post-nursing school perception of professionalism showed a significant 
difference in the post-nursing school perceptions. The interaction effect in Table 1 and Table 2 show the paired samples statistics T-test. Statement 1 (The role of the Registered Nurse is distinctive and contributes to the improvement of society) pre-nursing school perception ( $m=$ 4.7, $s d .5)$ and statement 1 post-nursing school perception ( $m=4.9, s d$.2). Significant increase was found from pre-nursing school perception to post-nursing school perception, $(t(215)=-5.6$, $p<.05$ ). Statement 2 (The Registered Nurse makes independent decisions concerning client care in the healthcare setting) pre-nursing school perception $(m=3.8, s d 1.08)$ and statement 2 postnursing school perception $(m=4.69, s d .516)$. Significant increase was found from pre-nursing school perception to post-nursing school perception, $(t(215)=-13.53, p<.05)$. Statement 3 (The Registered Nurse is successful in the role of advocate for the client in the healthcare setting) prenursing school perception $(m=4.47, s d .67)$ and statement 3 post-nursing school perception $(m=$ 4.89, sd .318). Significant increase was found from pre-nursing school perception to post-nursing school perception, $(t(215)=-10.47, p<.05)$. Statement 4 (The Registered Nurse can use teaching as an effective tool to improve the health status of the client) pre-nursing school perception ( $m=4.08, s d .43)$ and statement 4 post-nursing school perception $(m=4.9, s d .269)$. Significant increase was found from pre-nursing school perception to post-nursing school perception, $(t(215)=-3.84, p<.05)$. Statement 5 (The role of the Registered Nurse in a healthcare setting sets an example for other healthcare providers) pre-nursing school perception $(m=4.6, s d .55)$ and statement 5 post-nursing school perception $(m=5.12, s d 3.35)$. Significant increase was found from pre-nursing school perception to post-nursing school perception, $(t$ $(215)=-2.2, p<.05)$. Statement 6 (The Registered Nurse is an integral part of the multiple disciplinary approach to healthcare) pre-nursing school perception ( $m=4.65, s d .54)$ and statement 6 post-nursing school perception $(m=5.13, s d .23)$. 
Table 1. T-Tests

Paired Sample Statistics

\begin{tabular}{|ll|r|r|r|r|}
\hline & & Mean & $\mathrm{N}$ & \multicolumn{1}{c|}{$\begin{array}{c}\text { Std. } \\
\text { Deviation }\end{array}$} & $\begin{array}{c}\text { Std. Error } \\
\text { Mean }\end{array}$ \\
\hline Pair 1 & Q1PRE & 4.7361 & 216 & .51920 & .03533 \\
& Q1POST & 4.9352 & 216 & .24677 & .01679 \\
Pair 2 & Q2PRE & 3.8657 & 216 & 1.08928 & .07412 \\
& Q2POST & 4.6991 & 216 & .51688 & .03517 \\
Pair 3 & Q3PRE & 4.4722 & 216 & .67457 & .04590 \\
& Q3POST & 4.8981 & 216 & .31813 & .02165 \\
Pair 4 & Q4PRE & 4.8056 & 216 & .43043 & .02929 \\
& Q4POST & 4.9213 & 216 & .26990 & .01836 \\
Pair 5 & Q5PRE & 4.6111 & 216 & .55962 & .03808 \\
& Q5POST & 5.1250 & 216 & 3.35471 & .22826 \\
Pair 6 & Q6PRE & 4.6574 & 216 & .54835 & .03731 \\
& Q6POST & 5.1389 & 216 & 3.42211 & .23285 \\
Pair 7 & Q7PRE & 4.0509 & 216 & .95098 & .06471 \\
& Q7POST & 4.9722 & 216 & 3.45323 & .23496 \\
Pair 8 & Q8PRE & 4.4722 & 216 & .68822 & .04683 \\
& Q8POST & 4.8241 & 216 & .39364 & .02678 \\
& Q9PRE & 3.1435 & 216 & 1.26224 & .08588 \\
P9POST & 3.7500 & 216 & 1.05764 & .07196 \\
& Pre-nursing & 38.5417 & 216 & 5.03644 & .34269 \\
& & 216 & 4.23068 & .28786 \\
\hline
\end{tabular}


Table 2. T-Tests

Paired Samples Test

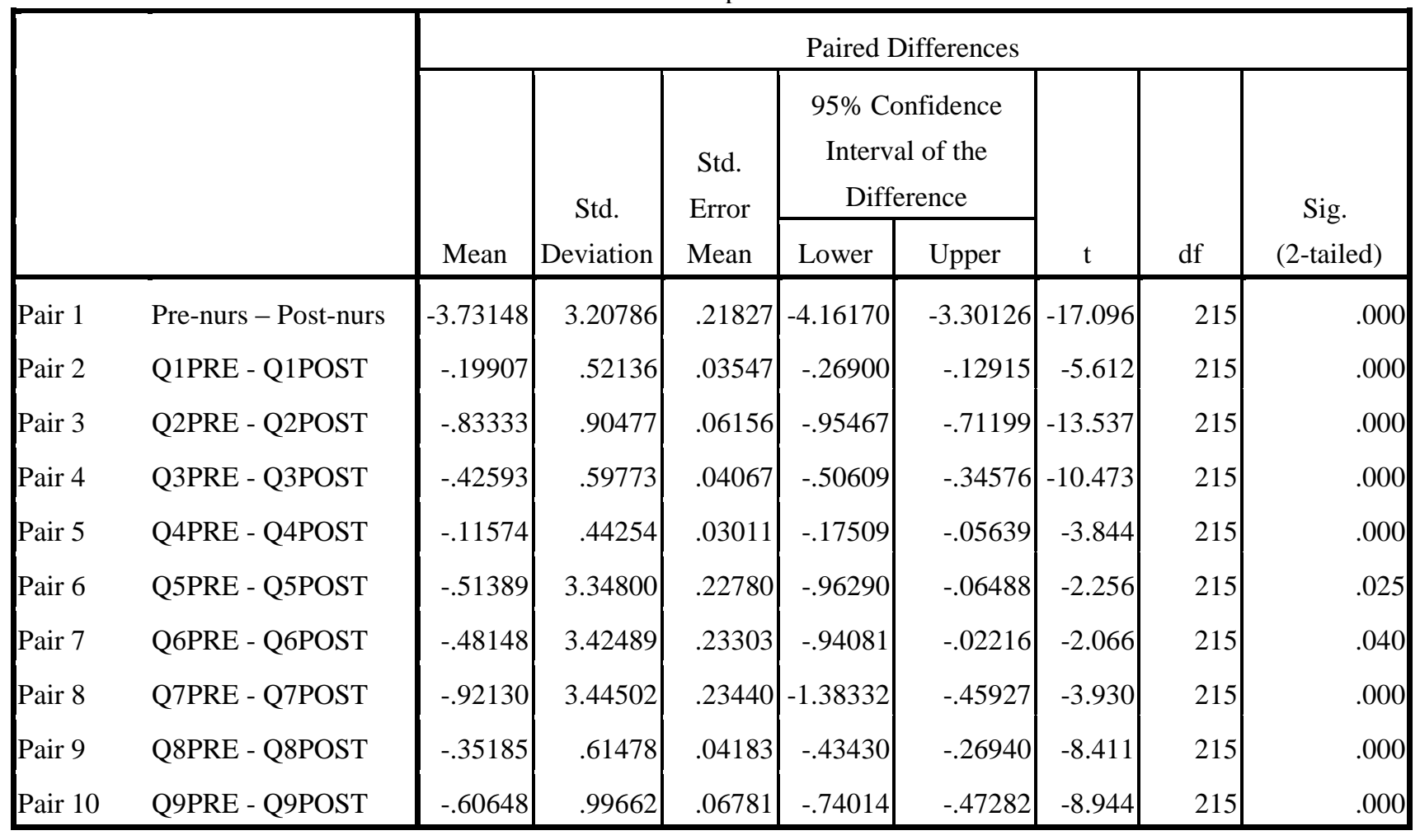


Significant increase was found from pre-nursing school perception to post-nursing school perception, $(t(215)=-2.06, p<.05)$. Statement 7 (The quality of client care is delivered at a higher measure when a Registered Nurse provides the care) pre-nursing school perception $(m=$ 4.05, sd .95) and statement 7 post-nursing school perception $(\mathrm{m}=4.9$, sd 3.45). Significant increase was found from pre-nursing school perception to post-nursing school perception, $(t$ $(215)=-3.9, p<.05)$. Statement 8 (Nursing research has a direct impact on the role of the Registered Nurse) pre-nursing school perception $(m=4.47, s d .688)$ and statement 8 postnursing school perception $(m=4.82, s d .39)$. Significant increase was found from pre-nursing school perception to post-nursing school perception, $(t(215)=-8.41, p<.05)$. Statement 9 (A prospective financially secure position is a major reason for choosing Registered Nurse as a profession) pre-nursing school perception $(m=3.14, s d 1.26)$ and statement 9 post-nursing school perception $(m=3.75, s d 1.05)$. Significant increase was found from pre-nursing school perception to post-nursing school perception, $(t(215)=-8.9, p<.05)$. The increase in the perception of nursing professionalism during the two-year associate degree nursing program can be connected to the educational process itself; in addition, nursing students also see nursing role models that promote professionalism. Table 1 shows the post-nursing school subjects rated nursing professionalism ( $m=42.28)$ significantly higher than pre-nursing school subjects $(m=38.54)$. The increase in the perception of nursing professionalism during the two-year associate degree nursing program can be connected to the educational process itself; the history of nursing, nursing research and the impact on nursing care, learning nursing theory and the nursing process as a guide to patient care are all explored. Nursing students also see nursing role models that promote professionalism, such as nursing professors, registered nurses in the hospitals and even fellow students who develop their nursing presence throughout the educational process. The 
nursing student's self concept may have increased and the student is feeling better about themselves and the choice they made to become a registered nurse.

A Factorial Analysis of Variance was calculated comparing education and gender for nursing students and is demonstrated in Table 3. Perception of Nursing Professionalism was used as the dependent variable, with results computed with the pre-nursing school perception and again for the post-nursing school perception. The main effect of pre-nursing school perception for formal education was significant $(\mathrm{F}(5,205)=6.7, p<.05)$ as was the post-nursing school perception $(\mathrm{F}(5,205)=13.8, p<.05)$. The slight increase from pre-nursing school perception to post-nursing school perception may be based on an original under estimation of the knowledge content needed for nursing. Nursing students who have obtained one or two year degrees in surgical technology, respiratory therapy or licensed practical nurse may not have discovered until they were actually in the registered nursing program how important nursing theory guides nursing actions. These other health science programs are offered at the community college and it is not unusual for students of one certification to change direction and decide to become a registered nurse. For both male and female students, who have limited and no formal education before enrolling in the college nursing program, the discovery that they have more intellectual ability than they previously thought affected their perception. The gain of formal education is a life changing experience for many students. The main effect of pre-nursing school perception for gender was significant $(\mathrm{F}(1,205)=20.7, p<.05)$ and increased in significance in the postnursing school perception $(\mathrm{F}(1,205)=61.5, p<.05)$. The male nursing students may have realized that their male minority status is valuable in not only getting a nursing position but also in advancement within the nursing field. The male nursing students may also have witnessed the number of male nurses in the nursing units and the establishment of male nurse role model may 
have increased the belief that being a male nurse can make a difference for nursing. Many male students attend nursing school after they have either lost a job or retired from an industrial setting and many of these people have no formal education, although they are rich in technical skills and experience in problem solving in the work place. The pre-nursing school perception interaction effect for formal education and gender was significant $(\mathrm{F}(4,205)=13.9, p<.05)$ and remained significant in the post-nursing school perception $(\mathrm{F}(4,205)=21.4, p<.05)$ demonstrating that the nursing curriculum did not have a strong result in changing those perceptions. 
Table 3. Factorial Analysis of Variance (ANOVA)

Between Subject Effects for Educational experience and Gender.

Tests of Between-Subjects Effects

Dependent Variable: Pre-nursing school

\begin{tabular}{|l|r|r|r|r|r|}
\hline Source & $\begin{array}{r}\text { Type III Sum of } \\
\text { Squares }\end{array}$ & Df & Mean Square & \multicolumn{1}{|c|}{$\mathrm{F}$} & \multicolumn{1}{c|}{ Sig. } \\
\hline Corrected Model & 1378.527 & 10 & 137.853 & 6.935 & .000 \\
Intercept & 37166.849 & 1 & 37166.849 & 1869.698 & .000 \\
Education & 667.605 & 5 & 133.521 & 6.717 & .000 \\
Gender & 412.823 & 1 & 412.823 & 20.767 & .000 \\
Education * Gender & 1102.249 & 4 & 275.562 & 13.862 & .000 \\
Error & 4075.098 & 205 & 19.879 & & \\
Total & 326313.000 & 216 & & & \\
Corrected Total & 5453.625 & 215 & & & \\
\hline
\end{tabular}

a. $\mathrm{R}$ Squared $=.253($ Adjusted $\mathrm{R}$ Squared $=.216)$

Tests of Between-Subjects Effects

Dependent Variable: Post-nursing school

\begin{tabular}{|l|r|r|r|r|r|}
\hline Source & $\begin{array}{c}\text { Type III Sum of } \\
\text { Squares }\end{array}$ & df & Mean Square & \multicolumn{1}{|c|}{$\mathrm{F}$} & \multicolumn{1}{c|}{ Sig. } \\
\hline Corrected Model & $1435.338^{\mathrm{a}}$ & 10 & 143.534 & 12.195 & .000 \\
Intercept & 42567.863 & 1 & 42567.863 & 3616.618 & .000 \\
Education & 812.649 & 5 & 162.530 & 13.809 & .000 \\
Gender & 723.324 & 1 & 723.324 & 61.455 & .000 \\
Education * Gender & 1007.815 & 4 & 251.954 & 21.406 & .000 \\
Error & 2412.865 & 205 & 11.770 & & \\
Total & 390098.000 & 216 & & & \\
Corrected Total & 3848.204 & 215 & & & \\
\hline
\end{tabular}

a. $\mathrm{R}$ Squared $=.373$ (Adjusted R Squared $=.342$ ) 
A Factorial Analysis of Variance was calculated comparing life experience (age) and salary focus (the importance of choosing nursing based on financial wellbeing) for nursing students and is illustrated in Table 4. Perception of Nursing Professionalism was used as the dependent variable, with results computed with the pre-nursing school perception and again for the post-nursing school perception. The main effect of pre-nursing school perception for life experience was significant $(\mathrm{F}(2,194)=4.3, p<.05)$ as was the main effect of post-nursing school perception for age experience $(\mathrm{F}(2,194)=6.06, p<.05)$ The increase from pre-nursing school perception and post-nursing school perception may reflect the nursing student realization that the age of registered nurses covers a wide spectrum, from early 20 s to early 60 s, causing middle aged nursing students to become more comfortable with becoming a nurse as a second career, a choice not uncommon within the community college student population.

The graduate registered nurse with no working experience has job opportunities and this may be very different aspect of age and employment from the graduate nurse's former experience. The main effect for pre-nursing school perception for salary focus was significant $(\mathrm{F}$ $(9,194)=3.4, p<.05)$ which remained significant with post-nursing school perception $(\mathrm{F}(9$, $194)=2.5, p<.05)$ with a slight decrease. Salary focus, or the importance of financial strength, changed with the financial incentives offered to new nurses and the nursing positions offered to graduating nursing students. The willingness of hospital units to employ and provide additional training (orientation to hospital and nursing unit) may have altered the perception of salary focus from becoming a nursing student and thinking it might happen to progressing to a graduate registered nurse for which the financial stability becomes a reality. The financial stability becomes a status attainable and consequently, less of a concern. The interaction effect for life experience and salary focus was significant for both pre-nursing school perception $(\mathrm{F}(10,194)=$ 
$2.8, p<.05)$ and post-nursing school perception $(\mathrm{F}(9,194)=2.5, p<.05)$. This reflects a slight decrease, although still significant, which may be explained by the registered nurse graduate who has been in the healthcare setting and may be more focused on making a difference in the lives of others resulting in the focus shifting from money to providing nursing care. 
Table 4. Factorial Analysis of Variance (ANOVA)

Between Subject Effects Life Experience (age) and Salary focus

Tests of Between-Subjects Effects

Dependent Variable: Pre-nursing school

\begin{tabular}{|l|r|r|r|r|r|}
\hline Source & $\begin{array}{c}\text { Type III Sum of } \\
\text { Squares }\end{array}$ & df & Mean Square & \multicolumn{1}{|c|}{$\mathrm{F}$} & Sig. \\
\hline Corrected Model & $1616.709^{\mathrm{a}}$ & 21 & 76.986 & 3.893 & .000 \\
Intercept & 48829.099 & 1 & 48829.099 & 2468.870 & .000 \\
Age & 172.064 & 2 & 86.032 & 4.350 & .014 \\
Salary & 613.025 & 9 & 68.114 & 3.444 & .001 \\
Age * Salary & 552.041 & 10 & 55.204 & 2.791 & .003 \\
Error & 3836.916 & 194 & 19.778 & & \\
Total & 326313.000 & 216 & & & \\
Corrected Total & 5453.625 & 215 & & & \\
\hline
\end{tabular}

a. R Squared $=.296$ (Adjusted R Squared $=.220)$

Tests of Between-Subjects Effects

Dependent Variable: Post-nursing school

\begin{tabular}{|l|r|r|r|r|r|}
\hline Source & $\begin{array}{c}\text { Type III Sum of } \\
\text { Squares }\end{array}$ & df & Mean Square & \multicolumn{1}{|c|}{$\mathrm{F}$} & Sig. \\
\hline Corrected Model & $918.256^{\mathrm{a}}$ & 21 & 43.726 & 2.895 & .000 \\
Intercept & 55880.620 & 1 & 55880.620 & 3700.012 & .000 \\
Age & 183.167 & 2 & 91.583 & 6.064 & .003 \\
Salary & 336.826 & 9 & 37.425 & 2.478 & .011 \\
Age * Salary & 624.815 & 10 & 62.481 & 4.137 & .000 \\
Error & 2929.948 & 194 & 15.103 & & \\
Total & 390098.000 & 216 & & & \\
Corrected Total & 3848.204 & 215 & & & \\
\hline
\end{tabular}

a. $\mathrm{R}$ Squared $=.239($ Adjusted R Squared $=.156)$ 
Interviews

\section{Chapter V}

\section{Introduction}

The interviews were conducted with each of the registered nurses interviewed separately and each from a different hospital; two nurses are employed in a rural hospital and two are employed in an urban hospital. There were three female nurses and one male nurse interviewed and each was a graduate from an associate degree nursing program. External and internal intrinsic motivators were revealed for continuing their nursing education to further the associate nursing degrees. External and internal intrinsic motivators and inhibitors were revealed for the role of the registered nurse and subsequently the quality of care the nurse could provide. Two of the registered nurses interviewed, in addition to being graduates of an associate degree program, participated in this research study as nursing students, completing the Registered Nursing Attitude Scale in their pre-nursing school and post-nursing school status. The interviews revealed the reality of being a registered nurse and were an important aspect of this study. The interviews with the nurses provided the insight into how they have translated the internalized concept of nursing professionalism as a nursing student into the actual authenticity of patient care in the hospital settings. The interviews are presented as rural health model followed by the urban hospital model and reveal the effect of power within the workplace for these nurses. Visualization of the themes for the registered nurse interviews are provided in Appendix B.

\section{Results}

The decision to interview registered nurses working in a healthcare setting was made after much thought into methods to discover the perceptions of the working nurse which adds another dimension to this research project. Four registered nurses agreed to participate in this portion of the study and two of those nurses participated in this study when they were nursing 
students. Two of the nurses currently work in a rural hospital and two in an urban hospital. The two models of hospitals used in this study are not exclusive to the study of all nursing experience but are used here to draw the content of nursing experience for registered nurses who are graduates of associate degree nursing programs. Nursing professionalism is associated with autonomy in providing nursing care, professional identity and the recognition of a national licensure and these two models were investigated to seek the perception of registered nurses working in the two different settings. Economic factors are often determined by the size of healthcare facility in which the registered nurse practices. Rural community hospitals fail to offer well paying jobs or adequate healthcare benefits to employees and often do not have medical specialists or the technologies for diagnostic evaluation. The failure of a multidisciplinary team to treat injuries initially can lead to longer recovery time and a higher risk of complications. Large medical centers with complicated technology make healthcare and the treatment of disease and injury more efficient than the rural community settings. The urban healthcare setting also often offers low cost clinics where patients can seek care, which increases the maintenance and promotion of health, prevention and treatment of disease and treatment of injuries (Murphy, 2004).

The California Workforce Initiative Survey (Seago \& Spetz, et al, 2003) addressed staffing ratios in both urban and rural settings in an effort to determine a state wide staffing ratio and what that impact had on nursing recruitment. Staffing ratios of registered nurse to patient and the combination of registered nurses, licensed practical nurses and unlicensed assistive personnel are promoted by administration as promoting patient care but are actually economic decisions. The study found that urban hospitals had more medical surgical units with higher patient census when compared to rural hospitals. The registered nurse average hours per day were very similar 
between urban and rural hospitals, with the rural hospital staff relying more on non registered nurse assistive personnel, including licensed practical nurses and unlicensed assistive personnel. Patient acuity refers to the health/disease status of the patient and the level of nursing care that would be required to provide quality patient nursing care. A higher patient acuity level for the hospital unit would require a higher number of registered nurses on duty and a smaller number of patients assigned to each nurse, recognizing and providing more time to be spent on each patient for nursing care.

\section{Rural Hospital Model}

Kathy, a 32-year old nurse who has been working in a small rural hospital for five years, is a graduate of a two-year associate degree nursing program. Kathy was interviewed because she is a full time employee of the hospital and she was on the nursing unit about 40 hours a week. I felt that this enabled her to understand more of how the unit works. Kathy also worked shifts occasionally in other medical surgical nursing units, so she had a unique perspective on how nursing functions within the hospital as different units have different staff and nursing managers. She was wearing a blue scrub uniform that designates her unit, her auburn hair was clean and styled and she wore light makeup with small gold earrings and a wrist watch. Her shoes were white and well kept. She wore a picture identification badge that identified her as a registered nurse and she had it clipped to her collar with her name and picture clearly visible. She agreed to meet with me after she had completed a daylight shift. We met in the hospital cafeteria and sat in a booth away from the few people that were in the cafeteria at that time. We had a light dessert and hot drinks, as the day was a cold and blustery one. Kathy stated that she was happy to contribute to the research project and easily remembered how she thought nursing would be when she was a student. She stated that it is definitely different, in both positive and negative 
ways. Kathy stated the rural hospital in which she works does not financially reward registered nurses for their educational level, so a registered nurse with an associate degree earns the same salary as a registered nurse with a baccalaureate degree in nursing. This is one major reason Kathy gave for the abundance of two-year degree registered nurses on staff in the hospital. The attainment of a higher nursing degree is not supported by any consideration for shift arrangement to include time off to attend classes. There is tuition reimbursement for college classes, but the money for the courses must be paid first by the nurse and then receipts and proof of attendance are submitted for financial reimbursement; for this arrangement, the nurse must agree to continue to be employed at the hospital for one year for each semester of education.

Kathy stated that she does feel that the few baccalaureate-prepared registered nurses working on her unit make sure that everyone knows they have a four-year degree, but that there is no consideration in scheduling or wages for it. She stated that professionalism is not determined by baccalaureate level but is evident in many nurses regardless of their degrees. Kathy smiled and stated that the school of nursing the nurse attended is a large determinant for professionalism. She stated that when students are expected to act professionally throughout school, they are more likely to continue to function professionally as a nurse. It appears to this writer that Kathy may have attended a nursing school in which more was expected of her, so I asked her and she replied yes. She stated that it bothers her to see nursing students on clinical rotation through her nursing unit fail to appear or act in a professional manner. When I asked her what was a professional manner to her, she replied that good grooming and actions based upon the desire to give good patient care. The most unprofessional nurses focus on themselves. Kathy's voice dropped, although we were seated away from anyone hearing, it appeared that being in the actual facility pressured her to be careful of what she was stating about the hospital. Kathy stated that 
administrative positions are not determined by nursing degree, but given to those known by present administrators. She stated that the registered nurses do not feel that attaining a higher degree would result in any of the supervisor or administrative jobs. She states that nurses can make lateral moves, from one unit to another for example, but are prevented from making promotions by this system. When I asked her if she had made any lateral moves, she stated that she started working in her current unit as a new graduate nurse and she has been happy with that choice.

Kathy states that the professionalism of nursing is not translated into nursing practice within her hospital. She states that it is personal integrity and personal professionalism within each nurse that makes the difference in the patients receiving good care. She believes that the current system of hospital administrators making the decisions about staffing of nurses in the units results in the nurses being powerless to the administrators. The staffing problem is complicated by patients today who are sicker than in the past. The lack of insurance for many people in this area and the loss of jobs have led to a lack of preventative health care, a lack of treatment of health alterations when they develop, and results in the admitting of many patients in crisis. Patients are also getting much younger with more serious health problems, such as diabetes and cardiac problems. Kathy stated that she will be transferring to work in the intensive care unit, in part because of the lack of recognition in higher patient acuity and inadequate staffing. She smiled and said that would be a lateral move for her but it feels like it is to a higher level of nursing. Kathy stated that there is closer contact with physicians in intensive nursing care and that physicians recognize the value of a registered nurse in making decisions about patient care more than administrators. She continued to describe that the view of the nursing staff concerning administrators was one of "us versus them" and states that administrators do not recognize the 
expertise of the registered nurse and take action to diminish any power the nurse holds. It appeared to this writer that the power of administration was making it more difficult for her to provide the quality care she desires. This has resulted in Kathy leaving the area of most pressure to one of lower pressure, from her current unit to the intensive care unit. It is fortunate for nursing that she is making a lateral move and is not leaving nursing, something that may happen with other nurses who do not have the strong desire to be a nurse that Kathy demonstrates. Kathy explained that when the hospital prepares media promotion, the administrators always use the nurses and nursing care as a strong motivation for patients to choose their hospital, which is in direct opposition to how the nurses feel that administrators treat nurses.

The shortage of registered nurses is felt within the smaller hospital and administrators will compensate with the low number of registered nurses on shift to an increase in unlicensed nursing personnel on shift, which greatly frustrates the nurses. Kathy furrowed her brow and appeared very serious, the most serious during the entire interview. She stated that there are fewer registered nurses to number of patients in the assignment and this is complicated by the decreased number of unlicensed assistive personnel. There is also an increase in the number of licensed practical nurses (LPN) assigned on each shift. This places a burden of responsibility on the registered nurse because the licensed practical nurses cannot administer many of the intravenous medications that are ordered, they cannot call the physician or take orders, cannot administer the first dose of antibiotic intravenous administrations, cannot administer narcotic intravenously and cannot care for a patient with a decreasing hemodynamic status. Everything the licensed practical nurse cannot do then goes to the registered nurse to do; this is in addition to the already established responsibilities for patient care for the registered nurse patient assignment. Kathy stated that she believes that this is evidence of administration not recognizing 
the worthiness of registered nurses and this is the most frustrating factor that she notes in her experience there. She states that this is another reason why she is moving to the intensive care unit; they do not have licensed practical nurses (LPN) practicing there. The increasing amount of paperwork for which the nurse is responsible is also very frustrating and she feels that much of it is unnecessary and prevents the nurse from having that time with the patient. Kathy also stated that there are constantly new "motivational efforts" made by the nursing unit administrators; the nursing staff feels that it has no meaning and is based on which particular seminar or workshop administration has recently attended. She appeared annoyed as she stated that it is demeaning to be treated to such nonsense.

The nursing meetings are also a sense of frustration among the staff as the meetings are promoted for communication but are more of one way communication of supervisor to nursing staff. Kathy appeared to relax and smiled again when she said she is most satisfied with knowing almost everyone who works in the hospital, from housekeeping to administration. The familiarity contributes to a more positive team effort and ease in tension. Kathy stated that she also likes that she works in a hospital in her community and feels a sense of pride that she is contributing to the wellbeing of the community. She said she also likes the short travel time and parking availability at her hospital. She also stated that the patients are her highest source of satisfaction and that she may be frustrated in unit politics but never forgets why she became a nurse, which was to deliver care to those who need it. She stated that the idea of providing patient care has not changed from how she thought it would be when she was a student. It is more complicated than she thought but much more rewarding than she ever imagined. Kathy stated that she loves nursing and wishes that more people understood what nurses do. I thanked her for sharing her time and perceptions with me and she stated that it was her pleasure. She provided her phone number to me in the 
event that I had any questions about what we discussed or had more questions. The cafeteria was just starting to get busy, there were several people in line and it was evident that we had picked the best time for privacy.

\section{Rural Hospital Model}

Karl, a 36-year-old registered nurse, has been working in a rural hospital for two years, and works extra shifts and with an even balance of night shifts and day shifts. I believe this provided him with an understanding of how his unit functions over the 24 hour period. He also works with a variety of staff since there are registered nurses and nursing support staff which work steady shifts. His blonde hair was clean and cut short and his face was clean shaven. He appeared trim and fit and smiled easily. He was wearing light blue scrubs and white shoes; he had a stethoscope around his neck and he had his identification badge clipped to his scrub shirt. He is a graduate of an associate degree nursing program. Karl agreed to meet with me in the morning, following a night turn shift. He appeared wide awake and stated he is pleased to be part of this study as a nurse. He participated in this study as a student.

We sat in a small area that allowed privacy on his unit and we were isolated enough that others could not hear our discussion. Karl stated that administration does put pressure on the nurses by requiring extra, unnecessary charting measures for which the nurse must initial each two hours that the patient has been checked for "pain, potty needs, and repositioned" and he grimaced when he spoke as if it was so disgusting that he hated to even discuss it. His complaint was that this " 3 Ps policy" is insulting to nurses who are doing their job as they should and is aimed at those who do not. Karl stated that putting a 3 Ps sheet on the patient door just invites those who don't do the patient care to check that they did. They do not even have to go into the patient room to mark the paper. He feels that unnecessary requirements like this are the focus of 
administration. Karl stated that if he is taking care of a patient that is unstable and needs his attention and nursing care and Karl does his nursing notes but fails to chart, as in marking on the 3 Ps sheet, it seems like administration focuses on the failure of marking the 3 Ps sheet and not on the care of the unstable patient, which is out of proportion. He stated that it seems as serious as if a nurse would not start a cardiac drip that was ordered and there is a big difference between what is harmful to the patient and what is not. Not double charting has no effect on the patient; failing to infuse a cardiac medication can be deadly for the patient. He stated that he does not understand or agree with it. Karl appeared frustrated and perplexed. He explained that it impacts patient care because sometimes you are trying to stay out of trouble by getting paperwork done, filling out forms instead of being with the patient in the room, providing comfort, repositioning or getting water that they need. He stated that he thinks administration gets in the way of patient care. It appears to this researcher that the very act that administration is encouraging, which is high quality patient care, is being prevented by the programs such as the 3 Ps for registered nurses who would provide that high level nursing care.

Karl stated that educational levels affecting patient care can be surprising and that there are some licensed practical nurses (LPN) that are better than registered nurses in providing care, checking orders, being careful to do things correctly, and charting. He said there is a difference in the education of the registered nurse as they learn more about disease processes and how to provide care at a higher level so they have a deeper understanding of what is happening with the patient status. Karl smiled and stated that patients want to be treated well and nicely because they are sick and miserable. Some licensed practical nurses (LPN) will do what is considered the little things like keeping water pitchers filled that are really important things to the patient. Registered nurses provide better nursing care that the licensed practical nurses (LPN) but it depends on the 
individual really. He stated that it has to go with how caring the nurses are and how well they provide care to the patient and it becomes evident in their nursing care. Karl stated that patients will request certain nurses. The difference in nursing education has to do with how dedicated the nurse is to patient care. Karl said that he is currently enrolled in a RN-BSN program which will start in May of this year. He stated that he is seeking the degree so there will be more doors open for him and for opportunity. Karl stated that he is happy with what he does now with no plans to go anywhere else at the present. He stated that education may help him deal with those power relationships he was talking about earlier. He said he feels the need to increase his knowledge and learn more for patient care and more nursing research and he smiled and stated he is looking forward to being a student again. Karl explained that the nursing shortage has caused an over abundance of overtime to be available. He stated that some people feel it is very good for the extra money and extra pay and some people feel very overworked. He said he feels that it affects the moral of nurses negatively, especially when a nurse is forced to work over after working a shift. Administration shows no concern if the nurse has a bad night, what the status of the patient assignment was, or if the nurse is tired. He stated that the low morale among the nurses negatively affects patient care; it directly reflects back to the patient.

Working in a community hospital has its advantages. Karl stated that some patients request him a lot and he really enjoys it and it makes him feel good that he provides the care that he does. Karl was smiling and his shoulders were back and head up looking proud and satisfied. He said he develops a professional relationship with the patients and a friendship within the professional relationship. Karl said that the likes the people with whom he works and stated that we have a close knit group that works night turn. We help each other out. This happens in a small environment that would not be in a large hospital. He stated that the most negative thing 
about working in a small hospital is the existence of the rumor mill. If a nurse makes a bad impression working on another floor, with management, or with the staff, the word spreads through the hospital and a bad reputation is established. The nurse is stamped with that and negative view travel faster than positive ones. Good impressions also follow you so it works both ways. This researcher thanked Karl for his time and participation and he stated that it was his pleasure. He stated that he understands the importance of nursing research and was happy to contribute to it.

\section{Urban Hospital Model.}

Karen is a 32 year-old registered nurse currently employed in a large, urban hospital. Karen is from my home community and she is an example of a young professional who designates 36 hours a week to her job. She is ambitious and comes from a family of nurses; her mother and two aunts are registered nurses. Her view of nursing added to this study because Karen has known about registered nursing since she was a child. Family members with college education also encouraged Karen to seek an education by example so I felt her outlook of continuing her education would be a valuable and unique view. She was dressed in casual clothes, jeans and a blouse with brown loafers. Her hair was dark brown and long and she had it pulled back in a soft ponytail. She wore silver hoop earrings, a pearl bracelet, a silver wristwatch and wedding rings. She agreed to meet me on a day off and we met at a small sandwich shop for lunch. The restaurant was moderately busy and we sat in a booth away from the other patrons so we would have more privacy to talk. There were a number of people seated at the counter talking to each other and to the waitress. Everyone was friendly and it was a relaxing atmosphere.

Karen is a graduate of an associate degree registered nurse program and has been working as a nurse for seven years. She stated that she came into the large hospital as a new 
graduate and that she has been working in the intensive care unit since that time. She stated that she wears light blue scrub uniforms for work and white shoes and feels that a neat appearance is the first step in projecting professionalism. Karen stated that she is open to participation in this research project and feels that nursing professionalism is on the decline with less well prepared nurses from schools which do not have any pride within their nursing program. She wondered how some of the nurses from these diploma type school programs even pass licensure boards to be registered nurses. Karen stated that most of the registered nurses in her unit have baccalaureate-degrees in nursing and are graduates from a large state university nearby, although there is probably about one fourth of the nursing unit with nurses with associate degrees, most of which travel into the city from outlying areas.

There is a difference in financial earning with the associate degree graduates earning less than baccalaureate prepared nurses. Karen stated that the charge nurses for her unit are all baccalaureate-prepared nurses and that she didn't know of any associate degree nurses that serve in the charge nurse position. She smiled when she stated that an associate degree nurse is prepared to adjust to any situation because the fast pace of the two-year program. These nurses adjust well to intensive care units and even the nurses who continue on to get additional degrees are clinically more competent if they initially had an associate degree. As Karen was telling her feelings on associate degree nurses, her back straightened and her head came up demonstrating pride in her degree of associate degree. She stated that all the nurses are encouraged to advance their degrees and that is throughout the hospital and not designated to any one unit. Karen stated that schedules are adjusted to allow the nurse to attend class and that the hospital has a tuition waiver program for the state university that is in close proximity to the hospital. If the nurse attends another college, tuition reimbursement repays the money spent without the nurse having 
to agree to any additional length of employment. She stated that she has been taking college classes at the state university close to the hospital with her goal to graduate in one more year with a baccalaureate-degree in nursing and returned to school to allow her to have more choices in nursing. She said she is interested in becoming a charge nurse but states that she has no ambition to go any further in administration. She stated that she feels she could bring a lot to the unit with her direction as charge and states that a shift can be positive or negative and much of the determinate is the charge nurse.

Karen stated that nursing professionalism does not seem to be tied to any nursing degree level. It may be more tied to age of the nurse as younger nurses do not always seem focused on patient care but more on getting out on time at the end of shift, often with plans to meet other members of staff for an evening of merrymaking. Karen said she feels that the physicians recognize the importance and value of a nurse and that most physicians treat the nurses with respect. When I asked for an example of this type of respect, she answered that a physician on morning rounds will ask the nurse about the patient and is open to information from the nurse for the status, such as the patient seems to be "dry" (dehydrated) and the physician will then order fluid to be infused. This is a teaching hospital, so both interns and physicians working to earn certification in intensive-care, are involved in patient care with the attending and surgical physicians. The nurse has the right and the responsibility to ensure that the intern or fellow does what is best for the patient. If there is an order that the nurse questions, the intern or fellow can reconsider or the nurse can always contact the attending physician. Karen laughed and stated that experienced interns and fellows advise the new interns and fellows to be respectful of the nurses and the nursing judgments because it is difficult to be successful if the nurse does not support them. She stated that the administration respects the nursing input on the status of the patients 
because they do consider the nurses' assessment of patient acuity and staffing needs when scheduling for the unit. The nurses sometimes are pulled to other units if they come into work and the acuity is down; the unit they work the shift is one in which the acuity is up. She stated that no one loves being pulled to another unit, but that each nurse understands that one nurse can make a difference in such a circumstance and nurses generally adjust their attitude and don't take it personally.

Karen said that she feels that professionalism is encouraged by the nursing staff and that the level of a nurse's professionalism is not necessarily determined by the nursing degree. Many of the associate degree prepared nurses are well respected but Karen does not feel that nurses have power within the work place. She stated that the hospital administrators do not value nursing professionalism that she learned in nursing school. Karen said that she feels that there will be cuts to benefits for nurses with time. It is the impression of this researcher that she has no trust in the hospital administration and believes that work benefits for nurses will decrease as work responsibilities for nurses will increase in the future, demonstrating a feeling of hopelessness. She gives the example that if tuition waivers had not already been in effect for years, the current administration would never have allowed the program to be established. Karen stated that the nursing shortage has provided an increase in wages and has allowed nurses to change units and even hospitals easily. Everyone understands that there is always an opening for a registered nurse in any health care setting. She stated that staffing is not really affected in her unit, but that more often the nurses from her unit are being pulled to step down units to help when they are short nurses. She stated that each year of employment the salary increases for registered nurses so most people are happy and moral within the unit is good. 
Karen stated that she is most frustrated about how administration makes the decisions concerning changing the type of nursing without the input of nurses who are working the units. For instance, in her time working she has done team nursing, in which there is a designated number of people on a team to provide care and their schedules rotate together. Karen stated that she has also done primary nursing, in which the nurse is always assigned to the same patient during that patient's unit stay. She shook her head and stated that although it sounds good to have the knowledge and familiarity with the patient condition to provide the most comprehensive care, it becomes an assignment nightmare when the nurse has two primary care assignments and the patients are situated on opposite ends of the unit. It causes less time available with each patient to provide care. It appeared to this writer that this is an example of the power of administration to control nursing care without regard to the logistics of the unit, something anyone working there could explain.

Karen smiled and stated that the greatest satisfaction in working at her hospital is in the freedom she feels by working three twelve hour shifts a week and receiving full time employment benefits. This allows her to have time with her family. She said that she also likes that there is usually overtime available when she wants it, so she may choose to work a little more if she wants to purchase a certain item. This makes her feel in control of her earnings and she says that is a great feeling of security. Karen stated that she loves working with the patients that her home community hospital life flights out for care and many times she will care for a patient in her unit, only to go home and see a story on the local news that tells of the accident or event resulting in the patient being transferred to her hospital and into her nursing unit. She stated that she travels forty five minutes each way between work and home and states that she does not mind the drive as it allows her to mentally prepare as she travels to work and to 
mentally decompress as she travels home. Karen stated that by working three twelve-hour shifts a week, which leaves her four days at home, it is a ratio that she loves.

\section{Urban Hospital Model}

Kim is a 36-year-old female registered nurse currently working in an urban hospital. She will soon be a single parent and will be responsible for her own welfare as well as that of her children. Her view of registered nursing is important to include because the nursing shortage and the continued need for healthcare almost guarantee her employment and a source of support. Kim is an example of a female using the empowerment of the profession to make her own way without any support dependency on her soon to be ex-husband. She arrived wearing a bright multicolored blouse and dark blue jeans. Her dark blond hair was clean and shiny and styled to a length just brushing the top of her shoulders. Kim was wearing light makeup and lip gloss. Her fingernails were painted a light pink and matched her toes that peaked from her sandals. She wore gold earrings and a silver and gold cross on a thin chain and a watch. She agreed to participate in this study and she met me in my home during a recent evening. She is legally separated and divorce proceedings are ongoing so she is attending meetings with lawyers and there are child custody issues that are being negotiated. Kim looked happy with a bright affect and ready smile. The power relationships within her unit are associated with computerized charting and medication administration. Kim stated that the programs were not created by a nurse or by anyone who understands what a nurse does. The computers are mounted on a moveable stand and she stated that the large units are a problem in small rooms. They are designed to prevent medication errors by having the drug, patient and nurse scanned. It is not completely effective and, if pharmacy makes a mistake and the nurse does not catch the mistake, 
the incorrect medication error can happen. Also, charting requirements change without any warning and that is disruptive.

Kim frowned and stated that recently her nurse manager became very critical of the nurses and staff, fired people without warning, and was writing everyone up (disciplinary action) for anything. The manager would send 50 erratic emails a day to the staff which did more to confuse than anything else. The tension in the unit was very high and the spirits were very low. Everyone was affected and afraid they were next. She had people in her office and these staff members said the nurse manager wanted them to tell on coworkers. It was very stressful. Kim said that the manager stopped the behavior and that staff is not sure if she is taking medication or if administration came down on her but there is a drastic change. Thing are returning to normal. The problem is that when you have a manager behaving in this manner, it causes patients to suffer because the nurse is afraid to do provide more care because of the fear of getting into trouble. There is no choice when a person is fired, they are gone. When a manager acts out, we must wait until something happens. We are powerless. It was evident to this researcher that this experience wounded Kim significantly. Her affect was flat by the time she finished talking about the abuses of the nurse manager and she appeared to be still depressed about the events. When I asked her about this, Kim stated that things went bad so fast and, although they are better now, she knows that it can happen again.

Kim stated that she is considering a move to another hospital because of the unrest. She stated that there are different educational levels in her unit. Most nurses on the floor are either certificate-diploma nurses or associate degree nurses. Once registered nurses get a four-year degree, they seem to move into administration. It opens the ability to become administrators and that moves the nurse away from patient care. Associate degree nurse are viewed as more 
educated, the diploma degree registered nurses are adequate in what they are doing but associate degree registered nurses have more understanding of what is happening. Kim said that diploma registered nurses know the procedure like starting a Cardizem drip for a patient with rapid atrial fibrillation, but do not consider if the patient has congestive heart failure or is in some phase of renal failure. The associate degree registered nurse has critical thinking skills that enable a better level of care for the patient. She said she has full intention to continue her nursing education to get her masters in nursing and become a nurse practitioner. Her brow furrowed and stated that school is not an option right now as she is a single parent with two children. There is also the problem of scheduling at work and they can request only two days for every six weeks so she can't arrange days to attend classes. Returning to college is something she will do in the future.

Kim stated that the nursing shortage cause fewer nurses to provide care and has a direct effect in her unit. The normal daylight patient assignment of five patients has become an eight patient assignment. High numbers of patients makes it more difficult to provide the level of care the patient deserves. Kim stated that there is also a decrease in the number of nurse aids and the ones we have are overworked. This is complicated by the physicians rounding, writing orders that are taken off by the unit secretary and faxed to pharmacy, dietary and testing, and checked by the charge nurse. Then a copy of the orders is made and put in the med room in a file with the name of the assigned nurse. It is the responsibility of the nurse to leave the patients and go to get those copies and act upon them. She stated that this may not sound like much, but the problem is that with more patients, the nurse is busier providing care and has less time to walk down the hall to the med room to get the orders at a time when there are even more orders there. It leaves less time with the patient. She said that this is not a problem specific to her unit but that it is no different between nursing units in her hospital, that all feel the nursing shortage. Kim stated that 
the administration does not like to pay higher wages to attract new nurses in a shortage but they must do so to be competitive. What they do is add more and more responsibility to the position so no nurse really benefits, they only appear to benefit.

Kim stated that she likes working in a large hospital because of the diversity. There are units like open heart, multiple intensive care units, women's health center, pediatric wing, cancer and radiation center and a large psychiatric unit. It is a resource center for care. Kim stated that she likes the telemetry unit caring for patients with congestive heart failure and renal failure. They are chronic conditions so the nurses get to know many of the patients and that is beneficial in providing nursing care. Kim sighed and stated that nurses are responsible for knowing the policies which the administration is constantly writing and changing policies and sending as emails to the nursing staff. The policy and procedure book is online and updated. The problem is that nurses are expected to read and know the policies and they can only access them using hospital computers which means more time away from patients. Kim stated that the patient is why she is in nursing and it is why she centered her entire life focus for two years of nursing school. She wants to take care of patients, to try to make change in their lives. That is why she is in nursing, for the patients. Themes are presented for the registered nurse interviews in Appendix B.

The nurse interviews were analyzed by reading and rereading the transcripts to discover significance and meaning. Thematic analysis of the data was completed seeking patterns and themes emergence, those both clear and suggestive (Bloomberg \& Volpe, 2008). Several major themes presented themselves in the data. Extrinsic motivators for continuing nursing education were identified as personal responsibilities, work schedules, and tuition benefits. This motivator theme demonstrated that, although nursing literature states that increasing the educational level 
of all registered nurses benefits nursing professionalism, in reality, administrative policies within a hospital can strongly affect nursing professionalism in a negative way by not providing the nurturing environment nurses need to continue education. The intrinsic themes of personal development and professional development demonstrated the influence nursing literature on the registered nurse affecting the perception that more formal education is both a personal and professional benefit. This theme was also associated with the registered nurse role models to which the nurses are exposed in their role as registered nurses. Administrative positions and charge nurse positions are two examples provided by the registered nurse interviews that were goals for the associate degree nursing graduate that encouraged them to seek more formal education.

The theme of extrinsic factors affecting the role of the nurse was identified as paper work, patient assignments and administration actions. This theme demonstrated the strong feeling registered nurses have for requirements and policies that they feel prevent them from having more time for patient care. Again, the power of the administration is evident in strongly affecting the role of the nurse which in turn affects patient care. Each of the nurses expressed frustration with these themes and tied them directly to lack of time to provide nursing care to patients. The theme of intrinsic factors was identified as self concept and patient focus demonstrate the power of self and professional worth by the nurses. The nurses again and again associated quality nursing care as care that is patient focused and demonstrated the belief that quality nursing care is connected to the registered nurses' personal and professional concept.

The theme of satisfaction with the working environment extrinsic factors included facility size, financial compensation and respect of the nursing staff by administration. The nurses who work in smaller hospitals expressed the positive attributes of the rural hospital while the nurses 
who work in larger hospitals voiced the positive attributes of the urban hospital which demonstrates that registered nurses seek employment where it is most fulfilling for them at the time. The power of administration is again demonstrated in being a strong factor in whether a nurse is satisfied within the facility or seeks to change. This theme's intrinsic factors were relationships with coworkers and relationships with patients and demonstrate the caring attitude associated with nursing. Coworker's focus on patient care was identified as improving patient care by the registered nurses and resulted in the delivery of a higher level of care.

The theme of the impact of the nursing shortage extrinsic factors included scheduling the number of registered nurses for each shift, scheduling the number of support staff for each shift and patient safety. This is an area in which the value of the coworker is demonstrated. When there are fewer registered nurses and support staff scheduled for a shift, if those people who are scheduled deliver a high quality of patient care, then fewer numbers are manageable. The scheduling was also tied to patient safety, with the belief that a lower registered nurse patient ratio promoted a higher quality of nursing care, including safety. The intrinsic factors for this theme were nurse fatigue and providing care which demonstrates that a registered nurse that is overworked is not as productive; that administrative policies that force overtime result in an erosion of morale and productivity. 


\section{Chapter VI}

\section{Nursing Educator Focus Group}

\section{Introduction}

The focus group of nursing educators reflected the perceptions of educators with varying degrees of teaching experience and varying levels of nursing education. These were the educators who present the nursing curriculum in both classroom and clinical practicum experiences for the nursing students, in effect the registered nurses who are responsible for instilling the traits of nursing professionalism in the nursing students. The subjects in the discussions among these educators were the traits of nursing professionalism and the promotion of nursing professionalism within the curriculum, the National Council Licensure Examination for Registered Nurses (NCLEX-RN), and nursing education degrees. The discussion of the educators revealed some of the external and internal intrinsic factors for continuing education that the registered nurse interviews exposed, demonstrating the importance of examining the effect of nursing curriculum and nursing education from this angle of perception. Visualization of the themes for the focus group is provided in Appendix C and Appendix D. This study sought to integrate the perceptions of the nursing school students, the registered nurses that are working in nursing units and nurse educators who present the nursing curriculum to the nursing students. It is only by seeking the views of each of these groups that we can begin to understand the development of nursing professionalism. As half of the registered nurses in this country received their nursing education in associate degree nursing programs, it is essential to understand the value of the education and how the nursing curriculum at the community college affects professionalism within the body of nursing. 
The decision to form a focus group of nursing educators was determined to be a good method to discover the perceptions of nursing professionalism among the faculty that contribute to the very development of professionalism in future nurses worldwide. This group would be instructors within my community; I contacted the educators through email and ask if they would be willing to stay after a day of teaching to meet with me. I also provided suggested discussion topics to encourage them to begin thinking about nursing professionalism and teaching. Teaching methods among nursing educators was recently studied to determine what type of evidencebased teaching practices were being used (Patterson, 2009). This was a national study which determined what triggers encourage faculty to reexamine teaching practices. Triggers were identified as wanting to try something new or teaching ineffectiveness as determined by student reaction. Evaluation of teaching was based on results of standardized testing, course grades and National Council Licensure Examination for Registered Nurses (NCLEX-RN) scores for licensure as a registered nurse. Another factor for change was the educational background of the nursing faculty as well as classroom size. Students again were important and feedback was valuable. Professional influence came from encouraging colleagues who shared their teaching practice techniques. Literature and information availability online was also a factor encouraging faculty to use nursing literature and evidenced based teaching methods. Facilitating factors were encouragement from administration, colleagues and students. Self confidence was also an important factor to facilitate change. Barriers were lack of time, increased workload and resistant colleagues. Most educators in the qualitative study expressed the importance of student success and were more likely to base a teaching practice on that success.

There were ten nursing educators who joined the roundtable discussion for purposes of this study. Five of the instructors are between 45-55 years old and the other five are between 25- 
35 years of age. Five of the instructors have been teaching nursing for 10-20 years and have been registered nurses for at least that long; the younger five educators have been teaching between two to six years and have been registered nurses for three to six years. The discussion started with the question, "How is professionalism defined in nursing?" Cathy stated that professionalism represents the nursing process in providing quality patient care; Katy stated that professionalism is treating patients with respect and dignity. It is also appearance and manner. Sue said she agreed and believes professionalism is behavior in both personal and professional roles. Brenda stated that with that behavior of respect and integrity is also kindness. Amy stated that it is acting in an ethical, safe manner for patients and self. Amy stated that commitment, accountability, knowledge, honesty and hard work are added to what everyone else has said. Barb added that in addition to being accountable and ethical, it is always keeping the patient as your top priority. Zoe stated that professionalism is a frame of mind and action that guides the behavior of how you look, speak, dress, learn and maintain optimism and accountability to exceed patients' expectations. Jen added that professionalism encompasses everything about the person: appearance, interactions with other people; verbal and nonverbal behaviors, and demonstrating respect and courtesy.

The next question, "How is professionalism promoted through nursing curriculum; is it lecture or clinical components?" Jane stated that professionalism is promoted through both phases of the educational process. It is promoted by role models for students, the faculty relationship with nursing staff and healthcare providers. Cathy said that professionalism is one of the overall goals of curriculum in both lecture and clinical as these are necessary components to reach the goal. Barb added that nurse educators can teach students how to be professional but it is up to the individual to internalize it to become part of them. Teachers can provide the tools but 
it is ultimately the responsibility of the person to be professional. Jen stated that professionalism needs to be promoted in all educational settings, classroom, clinical and all interactions. The faculty needs to demonstrate respect to the students, demonstrate professionalism in appearance and interactions to be a positive role model for students to follow. Katy and Zoe each stated that professionalism is a combination of lecture and clinical experiences. Brenda added that it is promoted through lecture and clinical and through classroom behavior toward the instructor and peers. It is also promoted through clinical practice with the instructor as role model, and in faculty relationships with staff members. Joy stated that the trick to promoting professionalism is to connect theory and clinical by applying the knowledge gained in the classroom into the clinical setting. Amy said that it is promoted more in clinical and less in lecture.

The third question, "What are the greatest concerns of the students regarding what they want to be taught? What are their greatest concerns?" Jen stated that students want the excitement of nursing in the emergency room, operating room, intensive care unit or cardiac care unit and that they are bored with theory. Students are concerned about their grades for theory and written clinical assignments. They are very task focused and desire to learn skills such as intravenous insertions. Cathy said students are concerned about getting an overall nursing education so they will be successful when sitting for the National Council Licensure Examination for Registered Nurses (NCLEX). They are also anxious about having the knowledge and skills for entry level employment in the profession. Barb added that she agreed and that students want to be able to function independently as a nurse. Amy stated that students are concerned that they can provide safe nursing care and that they can treat patients fairly and honestly with larger patient assignments. Zoe added that students are very focused on being able to function well clinically. Katy stated that they seem most concerned about passing each 
semester; the closer it gets to the end of the semester, the more concerned they become. Sue stated that some students just want to be taught what is on the National Council Licensure Examination for Registered Nurses (NCLEX) and others want to be taught "real life" nursing. They also want to be able to care for patients in the clinical setting. Brenda said students desire to pass each course and reach their goal of becoming a nurse.

The fourth question, "What as educators do you feel is the most important to teach and does this conflict with what students want?" Zoe stated that theory must be taught and students take time to process the importance of understanding theory as an essential component of nursing care. Without it, nurses are concrete thinkers and task oriented. It takes time for students to develop beyond this into critical thinkers and thought orientation. This helps them be successful with National Council Licensure Examination for Registered Nurses (NCLEX). Barb added that it is important to teach use of intuition and acceptance into the profession. Each year there are more questions on the National Council Licensure Examination for Registered Nurses (NCLEX) formatted as answer all that apply, instead of the standard design of multiple choice questions. Students must trust themselves. Critical thinking skills are important and enable the student to become an independently functioning nurse. Jen said that nursing is multifocal and education must include assessment, health promotion, communication, education aspects. The clash happens when students do not see the importance of this content into their practice. Brenda stated that safe and quality nursing care should be added to the list. Zoe feels that nursing theory is the most important content to teach because the students need to apply it into the clinical area. Jane added that self care is important to teach because without it, nurses can easily burn out. Amy states that educators must also teach to alleviate student education concerns. Many are worried 
about passing the National Council Licensure Examination for Registered Nurses (NCLEX) but it goes beyond that. They are motivated to learn and theory can become part of what is taught.

We took a 15 minute break and then regrouped.

The fifth question, "What is the difference in preparing students to function well in rural or urban settings?" Barb stated that smaller hospitals have less ancillary staff to help the nurse but it is balanced with patients with lower acuity levels. Smaller facilities have less money for technology and equipment. Sue said that larger hospitals have patients with higher levels of acuity and more specialized care, such as burn care, transplant organ units, and neonatal units. Cathy added that the overall basics of nursing care are similar, that the amount of clinical experience is more limited in rural settings. Either way, the prepared student must be clinically and theoretically ready to function in any setting. Brenda said that equipment may be newer in larger facilities, and more pay per hour, but the smaller hospitals may be friendlier, with more one-on-one interaction. Even though the smaller hospital resources may be limited, it would provide the nurse with opportunities to do more skills, such as electrocardiogram, intravenous or respiratory treatments because of less assistive personnel. Jane added that doing more skills is a consolation and that there is new equipment in larger facilities. Zoe stated that if the larger hospital is a teaching hospital, then there may be newer advances in addition to more advanced technology. Katy stated that teaching hospitals would involve residents and interns and that would complicate acclimating to a new unit and nursing care for a new nurse. Other than the teaching hospital differences, the overall basic nursing knowledge and care are pretty much the same in either rural or urban. Jen added agreement that hospital settings may vary but the nursing knowledge is basically the same and can be adapted to specialty units. Amy stated that the 
biggest challenge is preparing students to function safely in an understaffed hospital, no matter the size.

The sixth question, "What difference do you perceive as self concept between nurses according to nursing degrees? What about professional concept?" Amy stated that the more education a nurse gains, the higher personal and professional concept. Cathy said that clinical skills remain same but the theory knowledge creates an increased level of patient care so it is different professionally. Personal concept is affected only in an academic setting. Katy states that she feels that older, more experienced nurses with associate degrees or diploma degrees resent the nurses with higher degrees. I think this is tied more to the low self concept and self doubts. The younger nurses with higher degrees have a higher self concept and are confident. Sue stated that education is very important and it enhances the professional concept. Experience and life learning are more valuable in a clinical setting than a new graduate nurse with a higher degree. Jen added that self concept for most nurse increases with higher degrees attained. Joy stated that the self concept increases with degrees but the work ethic is determined from the first degree for the nurse. Barb said that there is not much difference between self concept between associate degree nurses and baccalaureate prepared nurses and the increase in self concept happens with graduate nursing degrees. Zoe added that she feels there is a difference between nursing degrees especially with older nurses. Brenda stated that higher educational degrees affect personal self concept and the increased knowledge increases professional self concept. Jane agreed and stated that higher degrees give the nurse educator more theoretical concepts.

The seventh question asked, "What was your initial nursing degree and why have you chosen to continue with your education?" Cathy stated that she graduated from a diploma nursing program and has continued education to improve employment status and future job 
opportunities. Joy said her initial nursing degree was as a licensed practical nurse and the return to school to become a registered nurse was for personal adventure and advancement. She will be returning to college to start on a Master's of Science in Nursing within the next year and that is for employment. She states that if she doesn't do it, she won't have a job teaching. (Everyone laughed). Jen stated that her initial degree was diploma and that she continued her education as personal and professional desire to increase knowledge, skills and effectiveness in her career. Barb said her initial degree was a baccalaureate nursing degree and then Master's of Science in Nursing and she is now currently working on a doctorate degree in nursing. She has continued for knowledge. She stated that as an educator, she feels it is her responsibility to continue with her education. Brenda stated her initial degree was a baccalaureate nursing degree and she has continued education because of love of teaching. She also wanted to learn more for personal growth. Jane added that her initial degree was baccalaureate nursing degree and she loved teaching and wanted to learn more so it would lead to her becoming a nursing instructor. Amy stated her initial degree was baccalaureate nursing degree, since that is what is required to teach nursing and she just continued on with her education. Katy said her initial degree was baccalaureate nursing degree and she has continued her education to become a better educator and advance her career. Sue said initial degree was associate degree and she has continued her education to fulfill her personal and professional goal of being a nursing educator. Zoe stated that her initial degree was baccalaureate nursing degree and she continued on with her education to become a better teacher and for career advancement. Themes for nurse educator interviews are presented in Appendix C.

The nurse educator focus group data was analyzed by reading and rereading the transcripts to discover significance and meaning. Analysis of the data was completed with the 
data grouped according into patterns and themes (Bloomberg, L. \& Volpe, M., 2008). Several major themes presented themselves in the data. The discussion on how professionalism is defined in nursing revealed major themes of integrity, quality delivery of nursing care and appearance. The theme of integrity demonstrated the characteristic identified with a registered nurse: honesty and truth. The quality of care theme provided the evidence of belief that the level of nursing care provided is a direct reflection back on the nurse's work. Clean, neat and tailored appearance was discussed as contributing to nursing professionalism. The discussion on how professionalism is promoted through the curriculum had major themes of lecture experiences, clinical experiences, all interactions and the role of faculty. This demonstrated that importance of professionalism being promoted throughout the curriculum and ingrained throughout the nursing education experience. It also highlighted the importance of nursing faculty in promoting professionalism as role models. How the students perceived the nursing faculty applying content into practice provides an example for the nursing student to follow.

The discussion concerning the greatest concerns of the nursing students in being taught exposed major themes of the National Council Licensure Examination for Registered Nurses (NCLEX-RN), evidenced-based practice (EBP), independence, and fear of future. This demonstrated the desire by the student nurse to succeed and also the fear of failure or fear of what the future may hold. The evidenced-based practice theme reflects the concern of the students being able to apply what they learn in lecture into the clinical practicum; this theme was also identified by the nursing educators as important in the discussion of the promoting professionalism within the clinical. The students are also fearful of functioning without a nursing instructor as a resource in the clinical setting. The themes were woven together and demonstrated the student perception of lack of self confidence and fear about being tested, formally and 
informally, on what they have learned. The discussion concerning what educators feel is most important to teach revealed the major themes of theory, National Council Licensure Examination for Registered Nurses (NCLEX-RN) and clinical competency. This focus by educators demonstrated the desire to teach the nursing students the theory which is the basis of the nursing actions, teaching associated with the development of nursing professionalism. Teaching clinical competency is one of the most challenging aspects of nursing education. It is in the clinical setting that the didactic concepts and theory are applied into the care of a patient. This was evidence of the desire of the educator to prepare the student to function well when they become a registered nurse. The importance of educating the students in the concepts they will need to be successful when they take the National Council Licensure Examination for Registered Nurses (NCLEX-RN) demonstrated a desire to prepare the student for success and also the pressure an educator experiences because successful National Council Licensure Examination for Registered Nurses (NCLEX-RN) rates is an important component of nursing program accreditation.

The discussion concerning how nursing educators perceived changes in self concepts of registered nurses within the roles of registered nurse demonstrated the themes of personal concept, professional concept, and attitude. The beliefs and experiences of the nursing educator influenced this discussion and it appeared to this researcher that each educator demonstrated passion when talking about these concepts. These themes demonstrated how the educator perceives self in the role of a nurse and how educators perceived others in the healthcare setting. The idea of personal concept encouraging professional concept was demonstrated here. The negative attitude of less educated nurses communicated to the educated nurses reflects a poor self concept and professional concept by the uneducated nurse. The discussion concerning why each educator has decided to continue seeking degrees beyond their initial nursing degree revealed 
major themes of personal growth, professional growth and employment requirements. These themes were evidence that there is some type of motivator pushing the registered nurse to continue with education. Many educators expressed personal growth which fostered professional growth. Other educators stated that employment requirements motivated them to continue, yet none of these nurses considered changing jobs, instead following the direction to get more education which revealed the desire of the nurse for further education. 


\section{Chapter VII}

\section{Conclusions}

In this conclusion, the historical events and social issues directly affecting the training, role and service of registered nurses in this country are discussed in relation to the many changes made in response to nursing shortages throughout history. The historical and social influences created concepts within the minds of the nurses, the educators, the hospital facilitators, and the public on general and specifics of how registered nurses should sound and perform. The effects of historical and social influences today and the ghostly images of the past still combine in determining the direction of nursing's concept of role, function and the influence on what educational level is acceptable for the registered nurse. Nursing professionalism is explored through the results of the nursing student surveys, registered nurses interviews, and a nursing educator focus group with a triangulation of the data which will provide a view of how different groups and levels of nursing are intertwined as integral pieces of nursing professionalism. Interventions to promote the growth of nursing professionalism within today's reality will be discussed. The future of the multiple entry level education dilemmas is discussed with thoughts on what a shared vision of institutions of higher learning and nursing organizations might accomplish.

The history of registered nursing strongly contributes to a patchwork effect of educational preparedness today. Florence Nightingale believed that training for nurses should be based upon practical scientific content so the nurse would become the skilled servant of health, hygiene and medicine and not function as a servant to physician or health officials (Holiday \& Parker, 1997). The early nineteenth century diploma programs for registered nurses provided three years of education but were focused on clinical competency (Joel, 2003) and the two-year associate 
degree programs for registered nurses were established in the early 1950s (Zerwekh \& Claborn, 2006). Associate degree nursing programs were developed in response to a nursing shortage and would supply registered nurses at a faster rate than the diploma-degree programs (Malka, 2007). The baccalaureate-degree nursing programs were started in the early 1920s (Catalano, 2006) and changed focus during the 1970s from the physician-controlled hospital setting to the community setting. This was done in an effort to foster autonomy and independence in the nursing students during the four year nursing program (Malka, 2007), both of these traits associated with nursing professionalism. Regardless of the educational path, the nursing student graduating from an accredited nursing program for registered nurses is considered qualified to take the National Council Licensing Examination for Registered Nurses (NCLEX-RN) for licensure as a registered nurse (Zerwekh \& Claborn, 2006). By this action, the nursing body itself continues to support and validate the inconsistency of educational preparation for registered nurses.

Nursing professionalism, as defined by Catalano (2006), has the traits of a high intellectual level, specialized body of knowledge learned in formal education, volunteer public service which is valued over financial gain; high degrees of autonomy and independence of practice, ethical behavior, strong professional identity and commitment to the profession, and professional competency and legal certification. The lack of standardized education for entry level into the role of registered nurse is a problem for nursing professionalism (Hood, 2010) and the educational process itself is viewed as responsible for instilling the knowledge and behaviors to promote the development of professionalism within nursing students. Nursing professionalism has primarily been promoted through the baccalaureate degree nursing programs. This leaves the concept that professionalism does not develop during the two-year associate degree nursing programs; this presents a problem as half of the total registered nurses practicing are graduates of 
associate degree nursing programs (Fetzer, 2003). Professionalism in nursing is perceived as being developed during the nursing education process and is cultivated when based on a nursing model and encouraged by the curriculum of the nursing program (Manninem 1998). Nursing research demonstrates the concept that nursing professionalism is an inductive process within the educational process of the nursing student when supported by nursing curriculum. There is a gap in the literature addressing how nursing professionalism is developed during the associate degree nursing programs or if it is developed at all (Cook, Gilmer \& Bess, 2003). This study investigated the development of nursing professionalism within the two-year associate degree nursing program. The research question, "What is the influence of nursing curriculum in associate degree nursing programs on the development of nursing professionalism in graduating nursing students?' has been explored.

\section{Triangulation of Data}

The nursing student perception of professionalism increased over the two-year educational process; this was in all areas of this study. This demonstrated that the nursing curriculum in lecture and clinical promoted the development of professionalism and that professionalism was encouraged and demonstrated through interactions with nursing faculty and registered nurses in the hospital where the students had their clinical experiences. The wide variety of life experience and educational experience at the community college setting may have contributed to the growing perception of professionalism of the nursing student. The community college student average age is young adult and this suggests a maturity and direction in the student's thoughts and actions. There is also the role modeling within the hospital that serves the community as many of the registered nurses employed at that facility are graduates of associate degree nursing programs. Nursing students are in contact with these nurses when they are in the 
hospital whether during nursing program clinical experiences or personal experiences, when the student or family member has been hospitalized. Many of the students may have family members or neighbors that are registered nurses; this information was not included on the survey. The concept of nursing professionalism in the graduating nursing student better prepares the new registered nurse to succeed in the role of the registered nurse. The focus on the patient and quality of care directs the focus from self (Radwin, 1998) and protects the registered nurse from absorbing much of the stress within any nursing unit, contributing to a successful experience as a registered nurse.

The registered nurses interviewed in this study expressed their pride in being a registered nurse and displayed a self concept of nursing professionalism. They also expressed that they seek evidence of professionalism in the role of other nurses within their own facility. The pressures felt by the registered nurses because of administrative policies resulted in a decrease in the quality time with patients, which caused the registered nurses' self view of professionalism to be strained. The role of administration appears to be the strongest factor detrimental to nurturing and developing nursing professionalism within the work place. The decisions of administration directly affect the quality of patient care delivered and the registered nurses felt that many administrative decisions are being made by non-nursing personnel. These registered nurses felt that administration is the major reason professionalism is being impaired in the hospital setting. Their views are supported by a study on job satisfaction for registered nurses (Zanagro \& Soeken, 2007) during which the researchers found that job satisfaction was negatively affected by stress and positively affected by autonomy.

Nursing educators focus on the development of nursing professionalism in the curriculum, from lecture to clinical to all interactions with the students. The faculty understood 
that they serve as role models for the nursing students and that the registered nurses working within the facility where the students have clinical rotations also have a strong impact on the view of professionalism for the student. Educators consciously focused on the development of nursing professionalism and did not appear to relax those standards during times of nursing shortages. The ethical and caring manner is essential for nursing students to develop and strong components of professionalism. Critical thinking was nurtured throughout the nursing program and autonomy was introduced during the last two semesters of nursing school and emphasized during the final semester before graduation. The educators expressed pressure from the National Council Licensure Examination for Registered Nurses (NCLEX-RN) results and understood that the success rate on graduates passing this certification test is a solid element in nursing program accreditation; yet it did not seem to be a focus in the teaching. Nursing educators serving in the role of preparing the nursing student to be able to function as a new graduate is supported by the study exploring the development of thinking like a nurse (Etheride, 2007) in which the new graduates increased their self concept and confidence as they become more aware of themselves and the role of registered nurse The confidence and accountability identified as being essential in the role of a registered nurse is developed over time and must begin in nursing school. Implications for professionalism promotion within current reality

The nursing curriculum does impact the development of professionalism in associate degree programs and this finding is supported by nursing students, registered nurses and nursing educators. The most gratifying aspect of this study is just how much nursing professionalism is a part of the professional lives of nursing students in their developmental process, registered nurses as they take their professional role into the ever changing world of health care, and the nurse educators who consciously prepare the students to develop nursing professionalism and then 
nurture and strengthen that trait so that the student nurse will take a self concept of nursing professionalism with them in their role of registered nurse. Nursing facilities and hospitals must improve the work environment for nurses and nurture the continued development of nursing professionalism. Providing patient care has been associated with nursing professionalism in this study and nursing administrators and decision makers need to work with nurses to establish policies that allow more time for patient care. The quality of care, something on which every nursing facility is rated, would actually increase with a decrease in stress and control of the nursing staff. It would be beneficial for the administrators, the nurses, and the patients. Nursing professionalism is part of the everyday dialogue for nursing students, registered nurses, and nurse educators, the development in nursing that is greatly beneficial to the body of nursing. Nursing curriculum and nurse educators introduce nursing professionalism to the nursing student, then the nursing student captures the content and nursing professionalism becomes internalized. As a new nursing graduate, that concept of nursing professionalism is carried with them into the work place. The new registered nurse is now empowered with nursing professionalism and is a role model to other workers within the healthcare field so the registered nurse may influence someone to become a nurse and the cycle begins again. The development and nurturing of professionalism has a direct impact on decreasing the nursing shortage and strengthening those registered nurses already functioning as healthcare providers.

\section{Implications for professionalism promotion within future reality}

The establishment of the baccalaureate education as the entrance level preparation for registered nurses by the American Nurses Association in 1965 (Catalano, 2006) and the National League of Nursing in 1982 (Mehaffey, 2002) recognized the problem of multiple educational levels in nursing. In the subsequent years, there have been debates and arguments about the 
problem of multiple educational entry levels for registered nurses, yet there still remain the three different entry educational levels. In addition, the nursing shortage that has discouraged any change in nursing education with the fear that any lessening of the nursing students being prepared would deepen the shortage not only remains today but is now a global problem. Associate degree nursing programs are popular because the educational opportunity is being offered right in the community in which the student lives. The removal of nursing programs from the community colleges would result in a drastic and far reaching decrease in the number of nursing students enrolled in nursing programs. It is the popularity of the community colleges themselves that has fueled the increased number of students seeking nursing education in associate degree programs. The American Association of Community Colleges (2010) provides the facts and research on community colleges. There are 1,173 community colleges within the United States with an enrollment of 11.8 million students enrolled in the fall of 2007. The average student attending a community college has a ten year gap from when he or she completed or were eligible to complete high school with a gender and racial composition of $56 \%$ female and $40 \%$ minority. The colleges within the community provide the opportunity for people of the community to attend college and earn their degrees while they are still in the community. This is another of the strengths of the community colleges; formatted to allow the student the ability to maintain employment while they are enrolled in college courses. Full time college students with full time employment hours are $21 \%$ of the student population; college schedules with part time employment hours $59 \%$ of the student body. It is clear that these community college students are attending college because the college is within the area where the student can navigate the world of responsibility with the world of academia. 
The successful completion of registered nursing licensure from the associate degree nursing programs provides the evidence that these programs should not be forsaken. The National Council of State Board of Nursing (2010) released the National Council Licensure Examination for Registered Nurses (NCLEX-RN) pass rates and for the last decade, the associate degree nursing graduate and the baccalaureate prepared nursing graduate score remarkably close each year; never more than two percentage points distance between the scores since 2000 . When we consider the differences within the student populations who took the test, we should remember that the community college students had an average age of 28 years and most students worked either full or part time employment while attending school. Many community college students have families and life responsibilities in addition to the college work. This demonstrates that community colleges are adequately preparing nursing students to become well prepared, safe and competent registered nurses. The research in this study shows that nursing professionalism does develop during those two years of study, yet the significance level suggests that the nursing professionalism, which is present in associate degree nursing graduates, is still developing and would deepen and mature with further education. It is within the grasp of nursing education to incorporate associate degree nursing programs by bringing college and university classes to the community colleges. The nursing program accreditation bodies can require associate degree nursing programs to be affiliated with a college or university which would allow the nursing students to continue their education for a baccalaureate nursing degree, which is the suggested entry level nursing degree for registered nurses. Those same nursing program accreditation bodies can require college and university nursing programs to be affiliated with a community college nursing program. It is within the grasp of nursing education to foster the educational growth of nursing students to promote the high level of nursing professionalism that is needed 
for the nursing profession, as well as for the personal and professional growth of all registered nurses.

Implications for Further Research

The development of nursing professionalism during the two-year associate degree nursing program that was evident in this study encourages the investigation of four-year baccalaureate degree nursing students at the two-year mark of their education. Would these results correspond to the same level of the development of nursing professionalism found in twoyear associate degree nursing students? Would the same results of the development of nursing professionalism be evident in two-year associate degree nursing students who are of a younger population than the one studied here? What is the effect of registered nurses who perceive a high level of nursing professionalism on the quality of nursing care provided to patients? Investigation into the perceptions of nursing professionalism by hospital administrators compared to the perceptions of nursing professionalism by the registered nursing staff would contribute to the awareness of the working reality for registered nurses. 


\section{References}

Allutto, J., Hrebiniak, L. \& Alonso, R. (1971). A study for differential socialization for members of one professional occupation. Journal of Health and Social Behavior, 12, 2, 140-147.

Angrist, S. (1965). Nursing care: the dream and the reality. The American Journal of Nursing, 65, 66-69.

Arhin, A. (2009). A pilot study of nursing students' perception of academic dishonesty: A generation y perspective. ABNF Journal, 17-21.

Behar, R. (1996). The vulnerable observer. Anthropology that breaks your heart. Massachusetts:Beacon.

Bell-Scriber, M. (2008) Warming the nursing education climate for traditional-age learners who are male. Nursing Education Perspectives, 29 (3), 143-150.

Billings, D. \& Halstead, J. (1998). Teaching in nursing: a guide for faculty. Philadelphia: Saunders.

Blakeley, J. \& Ribeiro, V. (2008). Early retirement among registered nurses: contributing factors. Journal of Nursing Education, 16, 29-37.

Blakemore \& Doult. (2009). Pledge to provide 3300 school nurses. Nursing Standard, 23, 28.

Bloomberg, L. \& Volpe, M. (2008). Completing your qualitative dissertation. Los Angeles: Sage.

Bond, M. (2009). Knowing in nursing: a concept analysis. Journal of Advanced Nursing Education, 48, 132-140.

Bonis, S. (2009). Knowing in nursing; a concept analysis. Journal of Advanced Nursing $65(6), 1328-1341$

Buerhaus, P., Donelan, K., Urich, B., Norman, L. \& Dittus, R. (2006). State of the registered 
nurse workforce in the U.S. Nursing Economics, 24, 1, 6-12.

Burns, N. \& Grove, S. (2003). Understanding Nursing Research. Saunders: USA.

Callister, L., Luthy, K., Thompson, P. \& Memmott, R. (2009). Ethical Reasoning in Baccalaureate Nursing Students. Nursing Ethics 16, 4, 499-510.

Carter, L. \& Rukholm, E. (2008). A study of critical thinking, teacher-student interactions, and discipline-specific writing in an online educational setting for registered nurses. Journal of Continuing Education in Nursing, March 39, 3, 133-138.

Catalano, J. (2006). Nursing now! Today's issues, tomorrow's trends. Philadelphia: F.A. Davis Company.

Chinn, P. \& Kramer, M. (1999). Theory and nursing: integrated knowledge development. Mosby: St. Louis.

Coleman, L. (2008). Experiences of African American students in a predominantly white, two-year nursing program. The ABNF Journal, Winter, 8-13.

Cook, T. H., Gilmer, M. J., \& Bess, C. J. (2003). Beginning students’ definitions of nursing: An inductive framework of professional identity. Journal of Nursing Education, 42, 311-318

DeYoung, S. (2003). Teaching strategies for nurse educators. New Jersey: Prentice Hall.

Etheridge, S. (2007). Learning to think like a nurse: Stories from new nurse graduates. The Journal of Continuing Education, 38, 1, 24-30.

Fetzer, S. J. (2003). Professionalism of associate degree nurses: The role of selfactualization. Nursing Education Perspectives, 24, 139-145.

Foxall, M., Megel, M., Grigsby, K. \& Billings, J. (2009). Faculty retirement-stemming the tide. Journal of Nursing Education, 49, 3, 172-175 
Freire, P. (2007). Pedagogy of the oppressed: $30^{\text {th }}$ anniversary edition. Translated by Myra Bergman Ramos. New York: Continuum International Publishing Group.

Gardner, J. (2005). A successful minority retention project. Journal of Nursing Education, 44, 566-568.

Giddens, J. (2009). Changing paradigms and challenging assumptions: Redefining quality and NCLEX-RN pass rates. Journal of Nursing Education, 48, 123-124.

Greene, Maxine. (2009) Curriculum and consciousness. In D. Flinders, Stephen Thornton (Eds.), The Curriculum Studies Reader. (pp. 155-167). New York: Rutledge.

Gordon, S. (2005). Nursing against the odds. New York: Cornell University.

Grumet, M. \& Stone, L. (2000). Feminism and curriculum: getting our act together. Journal of Curriculum Studies, 32 2, 183-197.

Haase, P. (1990). The origins and rise of associate degree nursing. Durham: Duke University Press.

Hanks, R. (2008). The lived experience of nursing advocacy. Nursing Ethics, 15, 458-477.

Hart, K. (2005). What do men in nursing really think? Nursing 2005, November, 46-48.

Hein, E. (2001). Nursing issues in the $21^{\text {st }}$ century: Perspectives from the literature. Philadephia: Lippincott.

Holiday, M. \& Parker, D. (1997). Florence Nightingale, feminism and nursing. Journal of Advanced Nursing, 26, 483-488.

Hood, L. (2010). Conceptual Bases of Professional Nursing. Philadelphia: Lippincott.

Hopkins, R. (2008). Early identification of at risk students: a student support model. Journal of Nursing Education, 47, 6, 254-259.

Houser, J. (2008). Nursing research: reading, using and creating evidence. MA: 
Jones and Bartlett.

Huston, C. (2010). Professional issues in nursing: challenges \& opportunities. $2^{\text {nd }}$ ed. Philadelphia: Lippincott.

Joel, L. (2003). Kelly's dimensions of professional nursing. New York: McGraw Hill.

LaSala, K. \& Nelson, J. (2005). What contributes to professionalism? MEDSURG Nursing, 14, 63-67.

Lindsay, G., Jeffrey, J. \& Singh, M. (2009). The Journal of Continuing Education, 40, 6, 181186.

Logan, D. \& Jones, W. (2008). Education news: Future faculty at Roxberry Community College. Nursing Education Perspectives, 29, 130-132.

Macnee, C. (2004). Understanding nursing research: Reading and using research in practice. Philadelphia: Lippincott.

Majaffey, E. (2002). The relevance of associate degree nursing education: past, present, future. Online Journal of Issues in Nursing, 7, 2, 11p.

Malka, Susan. (2007). Daring to care: American nursing and second wave feminism. Chicago: University of Illinois.

Manninen, E. (1998). Changes in nursing students' perceptions of nursing as they progress through their education. Journal of Advanced Nursing, 27, 390-399.

Martin, P., Yarbrough, S. \& Alfred, D. (2003). Professional values held by baccalaureate and associate degree nursing students. Journal of Nursing Scholarship, $3^{\text {rd }}$ quarter, 291-295.

McMillian, J., Morgan, S. \& Ament, P. (2006). Acceptance of male registered nurses by female registered nurses. Journal of Nursing Scholarship, $1^{\text {st }}$ quarter, 100-106. 
Mehaffey, E. (2002). The relevance of associate degree nursing education: past, present, future. Online Journal of Issues in Nursing, 7 (2). 11 p.

Mingo, A. (2008). Barriers and facilitators affecting African Americans continuation into graduate programs in nursing. ABNF Journal, Spring, 51-63.

Murphy, J. (2004). Care of the patient with traumatic brain injury: urban versus rural challenges. Topics in Emergency Medicine, 26, 4, 231-235.

Nightingale, F. (1969). Notes on nursing: What it is and what it is not. New York: Dover (Original work published 1860).

Norwood, S. (2000). Research strategies for advanced practice nurses. New Jersey: PrenticeHall.

Olson, J. \& Clough, M. (2001). Technology's tendency to undermine serious study: a cautionary note. The Clearing House, 75, 1, 8-13.

Patterson, B. (2009). The nature of evidence in teaching practice. Journal of Nursing Education, $48,6,327-333$.

Pender, N., Murdaugh, C. \& Parsons, M. (2002). Health promotion in nursing practice. New Jersey: Prentice Hall.

Phillepchuk, D. (2007). Describing and shaping RN practice. Alberta RN, 63, 4, 6p.

Pinkerton, S. (2001). The future of professionalism in nursing. Nursing Economics, 19, $130-131$.

Platzer, H., Blake, D., \& Ashford, D. (2000). An evaluation of process and outcomes from learning through reflective practice groups on a post-registration nursing course. Journal of Advanced Nursing, 31, 689-695.

Polit, D. \& Hungler, B. (1995). Nursing research: Principles and methods. Philadelphia: 
Lippincott.

Radwin, L. (1998). Empirically generated attributes of experience in nursing. Journal of Advanced Nursing, 27, 590-595.

Raines, C. \& Taglaireni, J. (2008)l. Career pathways in nursing: entry points and academic progression. Online Journal of Issues in Nursing, September, 13, 3, 11p.

Ronsten, B., Anderson, E. \& Gustafsson, B. (2005). Confirming mentorship. Journal of Nursing Management, 13, 312-321.

Salyers, V. (2005). Web-enhanced and face-to-face classroom instructional methods: effects on course outcomes and student satisfaction. International Journal of Nursing Education Scholarship, 2, 29, 1-11.

Seago, J. \& Spetz. J. (2005). California's minority majority and the white face of nursing. Journal of Nursing Education, 44, 555-562.

Seago, J., Spetz, J., Coffman, J. Kathynoff, E. \& O’Neal, E. (2003). Minimum staffing ratios: the California workforce initiative survey. Nursing Economics, 12, 2, 65-70.

Shaw, H. \& Degazon, C. (2008). Integrating the core professional values of nursing: a profession, not just a career. Journal of Cultural Diversity, 15, 44-50.

Shelton, E. (2003). Faculty support and student retention. Journal of Nursing Education, 42, 2, $68-75$.

Smith, G., Passmore, D. \& Faught, T. (2009). The challenges of online nursing education. Internet and Higher Education, 12, 96-103.

Thorpe, K. \& Loo, R. (2003). The values profile of nursing undergraduate students: Implications for education and professional development. Journal of Nursing Education, 42, 83-91.

Ward, M. \& Fetler, M. (1979). Instruments for use in nursing education research. Boulder: 
Western Interstate Commission for Higher Education.

Wilson, F. (1999). Measuring morality of justice and care among associate, baccalaureate and second career female nursing students. Journal of Social Behavior and Personality, 14, 597-607.

Zangaro, G. \& Soeken, K. (2007). A meta-analysis of studies of nurses' job satisfaction. Research in Nursing \& Health, 30, 445-448.

Zerwekh, J. \& Claborn, J. (2006). Nursing today: Transition and trends. Canada: Saunders.

Zucker, D. \& Asselin, M. (2003). Migrating to the web: the transformation of a traditional RN to BSN program. Journal of Continuing Education in Nursing, March/April, 34. 


\title{
Appendix A
}

\author{
Registered Nursing Attitude Scale \\ Names will be held in confidence and not released.
}

Name

Birth date $\_$Sex _ Highest educational level

Do you currently, or have you in the past, worked as a nursing assistant in a hospital setting?

If yes, how many years did you function in that position?

Are you currently employed as a nursing assistant in a hospital setting?

For the following statements, please respond with the degree to which you agree or disagree using the following scale.

\begin{tabular}{|c|c|c|c|c|}
\hline Strongly agree & Agree & No opinion & Disagree & Strongly disagree \\
5 & 4 & 3 & 2 & 1 \\
\hline
\end{tabular}

After reading each statement, mark you response in the blank provided.

- The role of the Registered Nurse is distinctive and contributes to the improvement of society.

- _ _ The Registered Nurse makes independent decisions concerning client care in the healthcare setting.

- The Registered Nurse is successful in the role of advocate for the client in the healthcare setting.

- _ The Registered Nurse can use teaching as an effective tool to improve the health status of the client.

- _ _ The role of the Registered Nurse in a healthcare setting sets an example for other healthcare providers.

- _ The Registered Nurse is an integral part of the multiple disciplinary approach to healthcare.

- The quality of client care is delivered at a higher measure when a Registered Nurse provides that care.

- A A prospective financially secure position is a major reason for choosing Registered Nursing as a profession.

- __ Nursing research has a direct impact on the role of the Registered Nurse. 


\section{Appendix B}

RN Motivators for Continuing Nursing Education

EXTRINSIC FACTORS

INTRINSIC FACTORS

\begin{tabular}{|l|c|c|c|c|c|}
\hline & $\begin{array}{c}\text { Personal } \\
\text { Responsibilities }\end{array}$ & $\begin{array}{c}\text { Work } \\
\text { Schedules }\end{array}$ & $\begin{array}{c}\text { Tuition } \\
\text { Benefits }\end{array}$ & $\begin{array}{c}\text { Desire for } \\
\text { Continuing } \\
\text { Education }\end{array}$ & $\begin{array}{c}\text { Professional } \\
\text { Development }\end{array}$ \\
\hline Kathy & $\mathrm{X}$ & $\mathrm{X}$ & $\mathrm{X}$ & & $\mathrm{X}$ \\
\hline Karen & & $\mathrm{X}$ & $\mathrm{X}$ & $\mathrm{X}$ & $\mathrm{X}$ \\
\hline Karl & $\mathrm{X}$ & $\mathrm{X}$ & & & $\mathrm{X}$ \\
\hline Kim & & & & \\
\hline
\end{tabular}

Dynamics affecting the Role of the Nurse EXTRINSIC FACTORS INTRINSIC FACTORS

\begin{tabular}{|l|c|c|c|c|c|}
\hline & $\begin{array}{c}\text { Paper } \\
\text { Work }\end{array}$ & $\begin{array}{c}\text { Patient } \\
\text { Assignments }\end{array}$ & Administration & $\begin{array}{c}\text { Self } \\
\text { Concept }\end{array}$ & $\begin{array}{l}\text { Patient } \\
\text { Focus }\end{array}$ \\
\hline Kathy & $\mathrm{X}$ & $\mathrm{X}$ & $\mathrm{X}$ & & $\mathrm{X}$ \\
\hline Karen & $\mathrm{X}$ & $\mathrm{X}$ & $\mathrm{X}$ & $\mathrm{X}$ & $\mathrm{X}$ \\
\hline Karl & $\mathrm{X}$ & $\mathrm{X}$ & $\mathrm{X}$ & $\mathrm{X}$ \\
\hline Kim & $\mathrm{X}$ & $\mathrm{X}$ & $\mathrm{X}$ & $\mathrm{X}$ & $\mathrm{X}$ \\
\hline
\end{tabular}

RN Satisfaction with Working Environment EXTRINSIC FACTORS INTRINSIC FACTORS

\begin{tabular}{|l|c|c|c|c|c|}
\hline & $\begin{array}{c}\text { Facility } \\
\text { Size }\end{array}$ & $\begin{array}{c}\text { Financial } \\
\text { Compensation }\end{array}$ & $\begin{array}{c}\text { Respect of } \\
\text { Administration }\end{array}$ & $\begin{array}{c}\text { Relationships } \\
\text { within } \\
\text { Coworkers }\end{array}$ & $\begin{array}{c}\text { Relationships } \\
\text { with } \\
\text { Patients }\end{array}$ \\
\hline Kathy & $\mathrm{X}$ & & $\mathrm{X}$ & $\mathrm{X}$ & $\mathrm{X}$ \\
\hline Karen & $\mathrm{X}$ & & $\mathrm{X}$ & & $\mathrm{X}$ \\
\hline Karl & $\mathrm{X}$ & $\mathrm{X}$ & $\mathrm{X}$ & $\mathrm{X}$ & $\mathrm{X}$ \\
\hline Kim & $\mathrm{X}$ & & $\mathrm{X}$ & $\mathrm{X}$ & $\mathrm{X}$ \\
\hline
\end{tabular}

Impact of Nursing Shortage

\begin{tabular}{|l|c|c|c|c|c|}
\cline { 2 - 6 } \multicolumn{4}{c|}{} & \multicolumn{3}{c|}{ EXTRINSIC FACTORS } & \multicolumn{2}{c|}{ INTRINSIC FACTORS } \\
\hline & $\begin{array}{c}\text { Staffing } \\
\text { Nurses }\end{array}$ & $\begin{array}{c}\text { Staffing } \\
\text { Staff }\end{array}$ & $\begin{array}{c}\text { Patient } \\
\text { Safety }\end{array}$ & $\begin{array}{c}\text { Nurse } \\
\text { Fatigue }\end{array}$ & $\begin{array}{c}\text { Providing } \\
\text { Care }\end{array}$ \\
\hline Kathy & $\mathrm{X}$ & $\mathrm{X}$ & $\mathrm{X}$ & & $\mathrm{X}$ \\
\hline Karen & & & & $\mathrm{X}$ & $\mathrm{X}$ \\
\hline Karl & & $\mathrm{X}$ & & & $\mathrm{X}$ \\
\hline Kim & $\mathrm{X}$ & $\mathrm{X}$ & & $\mathrm{X}$ \\
\hline
\end{tabular}




\section{Appendix C}

How do you as an RN define professionalism in nursing?

\begin{tabular}{|l|c|c|c|c|}
\hline & Integrity & Quality Care & Theory based & Appearance \\
\hline Cathy & & $\mathrm{X}$ & & \\
\hline Katy & $\mathrm{X}$ & & & $\mathrm{X}$ \\
\hline Sue & & & & \\
\hline Brenda & $\mathrm{X}$ & & $\mathrm{X}$ & \\
\hline Amy & & $\mathrm{X}$ & $\mathrm{X}$ & $\mathrm{X}$ \\
\hline Joy & $\mathrm{X}$ & $\mathrm{X}$ & $\mathrm{X}$ & \\
\hline Barb & $\mathrm{X}$ & $\mathrm{X}$ & $\mathrm{X}$ & \\
\hline Zoe & $\mathrm{X}$ & & & \\
\hline Jen & & & & \\
\hline Jane & & &
\end{tabular}

Do you believe that professionalism is promoted through curriculum and if so, lecture or clinical experiences?

\begin{tabular}{|l|c|c|c|c|}
\hline & Lecture & All interactions & Clinical & Faculty \\
\hline Cathy & $\mathrm{X}$ & & $\mathrm{X}$ & \\
\hline Katy & $\mathrm{X}$ & & $\mathrm{X}$ & \\
\hline Sue & & & & \\
\hline Brenda & $\mathrm{X}$ & $\mathrm{X}$ & $\mathrm{X}$ & \\
\hline Amy & $\mathrm{X}$ & & & \\
\hline Joy & $\mathrm{X}$ & & $\mathrm{X}$ & \\
\hline Barb & & $\mathrm{X}$ & & \\
\hline Zoe & & & & $\mathrm{X}$ \\
\hline Jen & $\mathrm{X}$ & $\mathrm{X}$ & $\mathrm{X}$ & $\mathrm{X}$ \\
\hline Jane & $\mathrm{X}$ & $\mathrm{X}$ & $\mathrm{X}$ & $\mathrm{X}$ \\
\hline
\end{tabular}

What do you feel are the students' greatest concerns?

\begin{tabular}{|l|c|c|c|c|}
\hline & NCLEX & $\begin{array}{c}\text { Evidenced Based } \\
\text { Practice }\end{array}$ & $\begin{array}{c}\text { Functions } \\
\text { Independently }\end{array}$ & $\begin{array}{c}\text { Fear of } \\
\text { Future }\end{array}$ \\
\hline Cathy & $\mathrm{X}$ & & $\mathrm{X}$ & \\
\hline Katy & & & $\mathrm{X}$ & $\mathrm{X}$ \\
\hline Sue & & & $\mathrm{X}$ & \\
\hline Brenda & $\mathrm{X}$ & & & \\
\hline Amy & & & $\mathrm{X}$ & \\
\hline Joy & & $\mathrm{X}$ & $\mathrm{X}$ & \\
\hline Barb & & & & $\mathrm{X}$ \\
\hline Zoe & & & & \\
\hline Jen & & & & \\
\hline Jane & & & & \\
\hline
\end{tabular}




\section{Appendix D}

What do you feel are the most important concepts to teach? Do you agree with the student or clash?

\begin{tabular}{|l|c|c|c|c|}
\hline & Theory & $\begin{array}{c}\text { NCLEX } \\
\text { preparation }\end{array}$ & $\begin{array}{c}\text { Clinical } \\
\text { Competency }\end{array}$ & \\
\hline Cathy & & & & \\
\hline Katy & $\mathrm{X}$ & & & \\
\hline Sue & & & & \\
\hline Brenda & & $\mathrm{X}$ & & \\
\hline Amy & $\mathrm{X}$ & $\mathrm{X}$ & & \\
\hline Joy & & $\mathrm{X}$ & & \\
\hline Barb & $\mathrm{X}$ & $\mathrm{X}$ & & \\
\hline Zoe & $\mathrm{X}$ & & $\mathrm{X}$ & \\
\hline Jen & & & & \\
\hline Jane & & & & \\
\hline
\end{tabular}

Do you believe that there is a difference personal self concept between nurses according to degrees?

\begin{tabular}{|l|c|c|c|c|}
\hline & $\begin{array}{c}\text { Personal } \\
\text { Concept }\end{array}$ & $\begin{array}{c}\text { Professional } \\
\text { Concept }\end{array}$ & $\begin{array}{c}\text { RN } \\
\text { Attitude }\end{array}$ & \\
\hline Cathy & $\mathrm{X}$ & $\mathrm{X}$ & & \\
\hline Katy & & & $\mathrm{X}$ & \\
\hline Sue & & $\mathrm{X}$ & & \\
\hline Brenda & $\mathrm{X}$ & $\mathrm{X}$ & & \\
\hline Amy & $\mathrm{X}$ & $\mathrm{X}$ & & \\
\hline Joy & & & & \\
\hline Barb & $\mathrm{X}$ & $\mathrm{X}$ & $\mathrm{X}$ & \\
\hline Zoe & & & $\mathrm{X}$ & \\
\hline Jen & & $\mathrm{X}$ & & \\
\hline Jane & & & & \\
\hline
\end{tabular}

Why did you continue with your education?

\begin{tabular}{|l|c|c|c|c|}
\hline & $\begin{array}{c}\text { Professional } \\
\text { Growth }\end{array}$ & $\begin{array}{c}\text { Required } \\
\text { for Employment }\end{array}$ & $\begin{array}{c}\text { Personal } \\
\text { Growth }\end{array}$ & \\
\hline Cathy & $\mathrm{X}$ & & & \\
\hline Katy & $\mathrm{X}$ & $\mathrm{X}$ & $\mathrm{X}$ & \\
\hline Sue & $\mathrm{X}$ & & $\mathrm{X}$ & \\
\hline Brenda & $\mathrm{X}$ & $\mathrm{X}$ & $\mathrm{X}$ & \\
\hline Amy & & & $\mathrm{X}$ & \\
\hline Joy & & $\mathrm{X}$ & $\mathrm{X}$ & \\
\hline Barb & $\mathrm{X}$ & & $\mathrm{X}$ & \\
\hline Zoe & $\mathrm{X}$ & $\mathrm{X}$ & $\mathrm{X}$ & \\
\hline Jen & $\mathrm{X}$ & $\mathrm{X}$ & & \\
\hline Jane & & & \\
\hline
\end{tabular}

